\title{
II. \\ Probleme des Wiederaufbaus
}

\section{Die tote Stadt}

\section{Neben den Ruinen blübt neues Leben}

„Auf den Ruinen Königsbergs bauen wir das sozialistische Kaliningrad“1 lautete Ende der vierziger Jahre die selbstgestellte Aufgabe der sowjetischen Planer für den Wiederaufbau der kriegzerstörten Stadt. Der Blick auf die Ruinen der ehemaligen Hauptstadt Ostpreußens war folglich ein Thema, das sich wie ein roter Faden durch die Geschichte des Wiederaufbaus von Kaliningrad zieht: Zuerst war dieser Blick noch sehr distanziert, es war der Blick von Eroberern auf eine ihnen „vom Anblick her fremde Stadt“2, der deshalb immer schon die Abgrenzung von der alten Architektur als Relikt der deutschen Kultur beinhaltete. Später verlor sich diese Distanz - die Ruinen mutierten zu einem Barometer, an dem der Erfolg des sowjetischen Aufbaus in Kaliningrad überprüft wurde.

In der Nachkriegszeit stellte sich bei vielen sowjetischen Betrachtern der Stadt angesichts der Zerstörungen zumindest ein Gefühl der Befriedigung ein, war doch das zerbombte Königsberg als Zeichen der deutschen Niederlage gleichzeitig auch Ausdruck des gerechten sowjetischen Sieges. Entsprechend positiv war das Bild, das sie von der Stadt und ihrem Wandel zeichneten, wie beispielsweise im folgenden Bericht eines auswärtigen Besuchers von 1951 über seine Ankunft in Kaliningrad. In diesem Text wird auch der bereits erwähnte Vorschlag behandelt, das alte Zentrum als Siegesdenkmal in seinem zerstörten Zustand zu belassen:

„Der Zug nähert sich Kaliningrad. ,Kaliningrad!' kündigt der Waggonschaffner laut an. Vor uns eröffnet sich ein unvergeßliches Panorama des niedergeworfenen Königsberg und im Aufbau befindlichen sozialistischen Kaliningrad. Es breitet sich in einer weiten Niederung aus. Was für eine Stadt! Die Straßenbahn führt uns durch buckelige und enge Straßen des ehemaligen Königsberg. Ehemalig deshalb, weil Königsberg tatsächlich eine ehemalige Stadt ist. Sie existiert nicht. Kilometerweit öffnet sich ein unvergeßliches Ruinengemälde. Dort stehen, eng aneinandergedrückt, zerstörte leere Häuser, ohne Dächer und Abdeckungen. Sie sind mit Unkraut und Efeu überwuchert. In jeder Ruine sprießt

1 So der Titel des ersten Artikels des Kaliningrader Chefarchitekten Navalichin, der am 15. Mai 1948 in der Kaliningradskaja Pravda abgedruckt wurde.

2 So Navalichin in: ders., Každoe novoe zdanie dolžno urkrašat' naš gorod, in: Kaliningrads kaja Pravda, 3. September 1949. 
ein kleiner Wald. Seitlich, inmitten der Ruinen, liegt das Schloß der drei Könige - eine Zitadelle, deren massive Mauern von der Zeit und vom Wetter geschwärzt sind.

Das alte Königsberg ist eine tote Stadt. Es wiederaufzubauen wäre sinnlos. Einfacher, praktischer ist es, eine neue Stadt zu bauen. Was aber mit der alten Stadt machen! Die Kaliningrader schlagen im Ernst vor, um das zerstörte Königsberg eine Mauer zu ziehen und von Zeit zu Zeit dorthin Anwärter auf die Weltherrschaft zu führen.

Dic Straßenbahn fährt zum neuen Zentrum der neuen Stadt: Zum Platz des Sieges oder, wie er vom Volk genannt wird, zum Platz der drei Marschälle 3 . [...] Hier konzentrieren sich dic Geschäfte, Bibliotheken, Kinos, der Zoologische Garten, das Stadion ,Dynamo', der Kultur- und Erholungspark - in einem Bezirk, wo vor sechs Jahren das historische Treffen zweier sowjetischer Armeen stattfand. Nun befindet sich hier das Zentrum Kaliningrads, schlägt der Lebenspuls der neuen Stadt."4

Dieser Blick auf die Stadt war der Versuch, das deutsche Königsberg und das sowjetische Kaliningrad als Antithese zu begreifen, als zwei Städte, die augenscheinlich nichts miteinander zu tun hatten. Diese Perspektive findet sich auch in den Ende der vierziger Jahre für die sowjetische Kinochronik (Wochenschau) gedrehten Beiträgen über Kaliningrad wieder. In diesen kurzen Berichten wurden den Kinozuschauern zwei völlig gegensätzliche Städte vorgestellt: auf der einen Seite das verfallene Stadtzentrum von Königsberg und auf der anderen Seite das wohlgeordnete sozialistische Kaliningrad.

Diese künstlich hergestellte Entgegensetzung von zwei vermeintlich voneinander unabhängigen Städten hatte jedoch nicht lange Bestand, und viele sowjetische Übersiedler konnten sie von Anfang an nicht nachvollziehen. Als einer dieser Übersiedler bei seiner Ankunft 1947 wie der eben zitierte Besucher einen Blick vom Bahnhof auf die tote Stadt warf, war ihm bereits bewußt, daß es keine zwei Städte gab - Kaliningrad war das lediglich umbenannte, aber immer noch weitgehend zerstörte, ehemalige Königsberg:

„Wir kamen an einem trüben, schmutzigen, düsteren und regnerischen Tag, dem 17. Januar 1947, in Königsberg an. Man entlud den Zug [mit den sowjetischen Übersiedlern] an zwei Holzbaracken, dort war auch der Wartesaal. [...] Nach einiger Zeit ging ich auf die Straße. Rechts und links war Sumpf und vor mir Trümmer. Ich ging auf eine unversehrt gebliebene Brücke in der heutigen Kievskaja-Straße. Ringsherum Stille und Ruinen. Links vom Bahndamm standen Hunderte deutscher Dampfloks. Ich schaute von der Brücke in Richtung Stadt: kein einziges Rauchwölkchen, kein Auto, kein Mensch - nur Ruinen. Eine solche Einöde! Und mir wurde so wehmütig ums Herz. Ich kehrte zurück und sagte zu Mama: ,Laß uns zurückfahren, bevor es zu spät ist.' Sie antwortete: ,Wir haben doch Geld bekommen', und beruhigte mich mit Müh und Not." ${ }^{\text {" }}$

3 Gemeint ist der Platz des Sieges, der 1946 für kurze Zeit den Namen „Platz der drei Marschälle" trug.

4 Na zapade - net bol’še vostočnoj Prussii, S. 14.

5 Erinnerung von Aleksandr Avgustovič Melngalv in: Matthes, Als Russe in Ostpreußen, S. 64 . 
Dieser Eindruck läßt sich leicht nachvollziehen, wenn man die Ergebnisse der 1948 von der Verwaltung des Chefarchitekten durchgeführten Inventarisierung der Gebäude Kaliningrads betrachtet. Von den vor 1940 in Königsberg bestehenden 13368 Häusern waren zum 1. Oktober 19488355 zerstört; das entsprach 62,4 Prozent der gesamten Bebauung. Von den ehemals 4896 Häusern der Innenstadt waren sogar nur 161 Gebäude, also drei Prozent der Vorkriegsbestandes, unbeschädigt. Von den vorwiegend in den Vororten gelegenen Einfamilienhäusern hatten immerhin 59 Prozent den Krieg überstanden. Von den geschätzten sechs Millionen Quadratmetern Wohnraum, die die Stadt vor dem Krieg besessen hatte, waren gerade 1,03 Millionen Quadratmeter mehr oder weniger bewohnbar geblieben 6 .

\section{Ein blinder Fleck}

Mit der Zeit paßten sich die offiziellen Beschreibungen der Stadt der Realität an, und somit fielen auch in ihnen Königsberg und Kaliningrad in eins. Eine der wesentlichen Ursachen für diesen Umschwung dürfte im äußerst langsamen Tempo des Wiederaufbaus der Stadt gelegen haben, wie der Ausschnitt des folgenden Kommentares verdeutlicht, der im Februar 1954 in der Kaliningradskaja Pravda veröffentlicht wurde. Der Autor wählte wieder die gleiche Route durch die Stadt wie der anfangs zitierte Besucher aus dem Jahr 1951, doch bewertete er das, was er sah, nun völlig anders:

„Wir haben im wesentlichen nur einen Zugang nach Kaliningrad: über die Haupteisenbahnlinien. Der Bahnhof stellt in seiner Art ein natürliches Stadttor dar, aber seht, was mit diesem Stadttor geschieht! Ein Mensch, der in Kaliningrad ankommt, fährt mit der Straßenbahn oder mit dem Auto zunächst einige Kilometer bis zum eigentlichen Zentrum durch die ungeheure Zone der ,toten Stadt', an ununterbrochenen Ruinen und Brachgclände vorbei.

Jede sowjetische Stadt hat schöne, wohl hergerichtete und hell erleuchtete Hauptstraßen. In Moskau ist das der Gorkij-Prospekt, in Leningrad der Nevskij, in Kiev der Kreščratik. Die Arbeitenden lieben sie, sie sind stolz auf sie, sie sind die beliebten Orte für die Erholung und zum Schlendern. Wir haben solche Magistralen bislang nicht. Viele bestehende und bebaute Straßen sind schlecht beleuchtet und schlecht ausgestattet. Wir haben einzelne schöne Gebäude, doch wir haben keine oder fast keine Straßen, die ein architektonisch abgeschlossenes Ensemble, eine architektonisch-künstlerische Einheit darstellen würden." "

Im gleichen Monat veröffentlichte die Kaliningradskaja Pravda einen Erlaß des Gebietsparteikomitees, in dem kritisiert wurde, daß nicht nur das ehemalige Zentrum in Ruinen läge, sondern selbst am Stalingrader Pro-

6 Alle Angaben zitiert nach: Navalichin, K voprosu rekonstrukcii centra goroda Kaliningrada, S. 35-37.

7 Zastroit' i blagoustroit' glavnye magistrali Kaliningrada, Leitartikel der Kaliningradskaja Pravda, 6. Februar 1954. 
spekt, der damaligen Hauptstraße der Stadt, noch etwa ein Drittel der Gebäude zerstört seien ${ }^{8}$. Die Ruinen wurden zunehmend auch deshalb als Belastung empfunden, da die sowjetische Architektur nicht ihrer Aufgabe nachkommen konnte, die „Erfolge des jungen Kaliningrader Gebietes bei der Entwicklung der Industrie, der Landwirtschaft und der Kultur"9 auszudrücken - nicht zuletzt deshalb, weil sich diese Erfolge in engen Grenzen hielten. Die Ruinen Königsbergs wurden somit von einem Zeichen des Sieges über die Deutschen zum Symbol für die wirtschaftliche Niederlage der Sowjetunion im Kaliningrader Gebiet.

Wenig erbaulich empfanden es die Kaliningrader deshalb, daß ihre Stadt aufgrund ihres ruinösen Zustandes unter sowjetischen Regisseuren ein beliebter Drehort für Kriegsfilme war - heroische Gefühle stellten sich bei den Einwohnern des ehemaligen Königsberg beim Anblick von zerschossenen Fassaden schon lange nicht mehr ein. Ende 1958 seufzte daher ein Deputierter des Kaliningrader Stadtsowjets in einem Sylvesterartikel in der Kaliningradskaja Pravda: „Wie soll Kaliningrad in den nächsten sieben Jahren werden? In erster Linie sollen die Schutthaufen und Ruinen verschwinden, die infolge der schweren Kämpfe zurückgeblieben sind. Mögen die Moskauer und Minsker zu uns zu Filmaufnahmen kommen, meinen die Arbeitenden, aber nicht, um in Kaliningrad ,Frontlandschaften' zu suchen, sondern um die Schönheit unserer Gartenstadt zu rühmen." 10 Bis dieser Wunsch in Erfüllung ging, sollte jedoch noch ein ganzes Jahrzehnt vergehen, in dem mindestens ein Dutzend weiterer Kriegsfilme vor der Kulisse Kaliningrads gedreht wurden ${ }^{11}$.

In der Zwischenzeit trugen die lokalen Autoritäten die Klagen über den kriegsähnlichen Zustand der Innenstadt bis nach Moskau: Im August 1962 berichtete der Vorsitzende des Gebietsexekutivkomitees, Ja. Prušinskij, dem Ministerrat der RSFSR, daß der Wiederaufbau des Kaliningrader Gebietes sehr langsam vor sich gehe und „nicht die gewachsenen Bedürfnisse der Bevölkerung befriedigt. Infolgedessen ist das Zentrum der Stadt Kaliningrad bis heute nicht wiederaufgebaut, die Versorgung der Bevölkerung mit Wasser, mit den Diensten des öffentlichen Nahverkehrs und anderen Alltagsbedürfnissen befindet sich auf einem niedrigen Niveau. Der halbzerstörte

$8 \mathrm{O}$ zastrojke i blagoustrojstve central'nich ulic i ploščadej goroda Kaliningrada, in: Kaliningradskaja Pravda, 3. Februar 1954.

9 Diese Aufgabe formulierte Navalichin noch 1955 in: ders., K voprosu architekturnoj rekonstrukcii Kaliningrada, S. $171 \mathrm{f}$.

10 P. Ryženko, Poželanija rodnomu Kaliningradu, in: Kaliningradskaja Pravda, 30. Dezember 1958.

$11 \mathrm{Zu}$ den bekanntesten zählen: „Sudba čeloveka“ (Ein Menschenschicksal) von S. Bondarčuk aus dem Jahr 1959, „Otec soldata“ (Der Vater des Soldaten) von R. Čcheidse aus dem Jahr 1964 und „Vesna na Odere“ (Frühling an der Oder) von L Saakov aus dem Jahre 1967. Diese Filme waren auch in der DDR zu sehen und werden zum Teil im Bundesarchiv-Filmarchiv in Berlin aufbewahrt. 
Zustand des Zentrums der Stadt ruft bei den Arbeitern des Gebietes einen bedrückenden Eindruck hervor, er erinnert an die Jahre des Krieges; der Verfall zieht auch die Aufmerksamkeit westlicher Führer auf sich."12 Bereits zwei Jahre zuvor hatte der Parteichef des Kaliningrader Gebietes, F. Markov, in einem Brief an das Zentralkomitee der KPdSU ähnliche Formulierungen benutzt, um auf die schlechte Stimmungslage im Gebiet aufmerksam zu machen. Auf dieses Schreiben erhielt Markov offensichtlich keine Antwort. ${ }^{13}$ Es ist deshalb wenig verwunderlich, daß auch diese Klagen gegenüber dem Ministerrat und dem ZK zunächst wenig am Zustand der Kaliningrader Innenstadt änderten: Die vergleichsweise zaghaften Aufbauerfolge der ersten Hälfte der sechziger Jahre hatten es schwer, sich im Schatten der Ruinen zu behaupten. Diesen Eindruck versuchte 1964 der Architekt C. Grin'kov in einem Artikel über das Zentrum Kaliningrads abzuschwächen, für den auch er wieder den Blickwinkel eines am Bahnhof Ankommenden wählte:

„Wenn Sie vom Südbahnhof durch die Eisenbahnstraße gehen und an der Bahnüberführung rechts abbiegen, sehen Sie vor sich ein breites Panorama. Auf der Linken, so weit das Auge reicht, erblicken Sie Häuser. Dutzende heller Gebäudeblocks erheben sich an der Žitomirskaja Straße, am Lenin-Prospekt, an der Ševčenko Straße und an der Proletarskaja Straße. Zur Rechten, vom Bahnhof bis zur Pregelbrücke, spannt sich eine Reihe neuer fünfstöckiger Gebäude entlang des Lenin-Prospektes. Und nur geradeaus, rechts vom ehemaligen Schloß, ist noch ein offener Raum geblieben. Wie sehr wünschen wir Kaliningrader uns, daß dieser Teil der Stadt bebaut wird, damit die Ruinen und Brachflächen vollständig verschwinden!"14

Offensichtlich hielt Grin'kov die Tatsache, daß es in einigen Bereichen des Kaliningrader Stadtzentrums viele Häuser gab, für besonders hervorhebenswert - war sich der Autor doch bewußt, daß diese für Innenstädte eigentlich normale Situation im Kaliningrader Fall noch die Ausnahme bildete, wie dies seine anschließenden Bemerkungen über die noch verbliebenen Ruinen andeuten. Tatsächlich war nämlich die von Grin'kov beschriebene Nord-Süd-Verbindung durch das alte Zentrum, der LeninProspekt, Mitte der sechziger Jahre wenig mehr als eine Schneise durch das Brachgelände des ehemaligen Königsberg. So beklagte sich im März 1964 der damalige Chefarchitekt Vladimir Chodakovskij, Kaliningrad sei die „einzige immer noch stark zerstörte Großstadt“ der Sowjetunion ${ }^{15}$. Der

12 GAKO, f. 297, op. 8, d. 593, 1. 158, Kopie des Briefes des Vorsitzenden des Kaliningrader Gebictsexekutivkomitees, Ja. Prušinskij, an den Ministerrat der RSFSR, vom 10. August 1962.

13 CChIDNIKO, f. 1, op. 32, d. 86, 1. 6-8, Brief des Ersten Sekretärs des Kaliningrader Gcbietskomitees der KPdSU, F. Markov, an das ZK der KPdSU vom 8. April 1960. Gleichlautende Fassungen dieses Briefes sind am 3. Mai und 11. Juli des gleichen Jahres an das ZK der KPdSU geschickt worden.

14 Grin'kov, Molodet' rodnomu gorodu!, in: Kaliningradskaja Pravda, 4. April 1964.

15 Doklad glavnogo architektora goroda Kaliningrada tov. Chodakovskij, V. V., in: Materialy 
Vorsitzende des Stadtexekutivkomitees (Gorispolkom), N. Loškarev, hatte der Staatlichen Kommission für Bauangelegenheiten der RSFSR (Gosstroj) einen Monat zuvor mitgeteilt, daß bis dato nur fünf Prozent der früher im „zentralen Bereich der Stadt Kaliningrad“ bestehenden Gebäude wiederaufgebaut oder neuerrichtet worden seien ${ }^{16}$. Auch wenn also die Ruinen selbst langsam aus dem Stadtbild verschwanden, so traten doch an ihre Stelle selten neue Bauten. Die Beseitigung der Ruinen diente deshalb häufig nicht der tatsächlichen Bauvorbereitung, sondern in erster Linie der kosmetischen Herrichtung der Stadtlandschaft: Noch 1967 forderte der Chef der Gebietsverwaltung für Architektur, V. Charlamov, in einer Stellungnahme für das Gebietsexekutivkomitee, „spezielle Mittel für die Beseitigung der Ruinen zur Verfügung zu stellen, um diese Territorien in Grünanlagen und Blumenrabatten umzuwandeln" - die später einmal mit zeitgemäßen Gebäuden bebaut werden könnten ${ }^{17}$. Fast zwei Jahre später wurde jedoch in einem Artikel, den die Kaliningradskaja Pravda am 6. September 1968 veröffentlichte, beklagt, daß im Zentrum immer noch Reste zerstörter Gebäude zu finden seien, was die Bauarbeiten verzögere ${ }^{18}$.

In den Stadtführern der sechziger Jahre blieb die Gegenwart des Stadtzentrums angesichts dieses Zustandes weiterhin ein blinder Fleck: Die Beschreibung des sowjetischen Kaliningrad machte vom Südbahnhof gleich einen Sprung zum Platz des Sieges. Was dazwischen lag, hatte eine Vergangenheit, unter anderem als Schauplatz der Kapitulation von General Lasch nach der Erstürmung Königsbergs, aber nur eine vage Zukunft ${ }^{19}$. Obwohl in den vergangenen Jahren viel geschafft worden sei, so hatte C. Grin'kov denn auch im April 1964 in der Kaliningradskaja Pravda geschrieben, wüßten die Kaliningrader doch, „daß der Anblick der Stadt noch sehr weit von ihrer Vollkommenheit entfernt ist"20.

Der nur zögerlich voranschreitende Wiederaufbau Kaliningrads führte bald auch zu einer Neubewertung des alten Königsberg. So versicherte zum Beispiel im Juli 1955 der damalige Chefarchitekt von Kaliningrad,

soveščanija po proektirovaniju centra goroda Kaliningrada. Soveščanie sostojaloš’ 26.-27. Marta 1964 v g. Kaliningrade, Kaliningrad 1964, S. 3-9, hier: S. 3.

16 GAKO, f. 522, op. 1, d. 133, 1. 1 f., Brief des Vorsitzenden des Kaliningrader Stadtexckutivkomitees, Loškarev, an Gosstroj RSFSR vom 1. Februar 1964.

17 GAKO, f. 297, op. 8, d. 2030, 1. 12-14, Stellungnahme des Leiters der Verwaltung für Architektur des Kaliningrader Gebietes, V. Charlamov, „Über einige nichtentschiedene Fragen der Verbesserung der Planung des Aufbaus von Städten und Dörfern im Kaliningrader Gebiet“ vom 19. Januar 1967. Charlamov bezog sich bei seiner Aussage neben Kaliningrad auch auf die Städte Bagrationovsk, Pravdinsk und Mamonova.

18 Vgl. „Podgotovka k stroitel'stvu centra Kaliningrada“, in: Kaliningradskaja Pravda, 6. Scptember 1968.

19 Vgl. Kolganova, Putešestvujte po Kaliningradskoj oblasti, S. 17-19 (über die alte Innenstadt in Gegenwart und Zukunft) und S. 91-119 (über die Vergangenheit der alten Innenstadt); dies., Putešestvujte po Kaliningrad, S. 26-31 (über die Kämpfe in der Innenstadt und dic Kapitualtion von Lasch) und S. 36-43 (über dic Baudenkmäler in der Innenstadt).

20 Grin'kov, Molodet' rodnomu gorodu!, in: Kaliningradskaja Pravda, 4. April 1964. 
K. Ja. Chrustalev, auf einer Versammlung der Kaliningrader Abteilung der Union der Architekten der Sowjetunion (KOSA) zwar, das gegenwärtige Kaliningrad mache einen guten Eindruck, doch gestand er zu, daß auf die Kaliningrader Architekten „noch viel Arbeit zukommt, um aus Kaliningrad eine schönere und bessere Stadt zu machen, als sie unter den Deutschen gewesen ist" 21 . Der Eindruck der Wiederaufbauprobleme hatte somit zumindest bei einem Teil der Kaliningrader eine bemerkenswerte Wandlung ihres Bildes von der ehemaligen Hauptstadt Ostpreußens bewirkt: Von der bösen Stadt entwickelte sich Königsberg zur Meßlatte des gegenwärtigen Kaliningrad. Hatte Navalichin noch Ende der vierziger Jahre betont, die Anforderungen, die der sowjetische Mensch an seine sozialistische Stadt stelle, seien „bedeutend höher als die Prinzipien der Planung und Normen, die in kapitalistischen Ländern gelten“22, so wurde ab 1956 selbst in Briefen des Gebietsexekutivkomitees und der Parteispitze des Kaliningrader Gebietes an die Moskauer Zentralen regelmäßig explizit auf den Wohnraumbestand des ehemaligen Königsberg Bezug genommen ${ }^{23}$. Während sich die durchschnittliche Versorgung der Kaliningrader Bevölkerung mit Wohnraum im sowjetischen Vergleich durchaus sehen lassen konnte24, war der absolute Wohnraumbestand im Vergleich zum Vorkriegsniveau erschreckend niedrig $^{25}$ : Der Königsberger Vorkriegsbestand an Wohnraum (1939) wurde auf

21 GAKO, f. 135, op. 1, d. 60, Protokoll der allgemeinen Versammlung der Mitglieder der Kaliningrader Abteilung der Union der Architekten der Sowjetunion am 30. Juli 1955.

22 Navalichin, $\mathrm{Na}$ razvalinach Kenigsberga postroim socialističeskij Kaliningrad, in: Kaliningradskaja Pravda, 15. Mai 1948.

23 GAKO, f. 297, op. 8, d. 593, 1. 17, Brief des Sekretärs des Gebietsexekutivkomitees an den Ministerrat der RSFSR vom 13. April 1956; CChIDNIKO, f. 1, op. 32, d. 86, 1. 6-8, Brief des Parteichefs der Kaliningrader Gebietes, F. Markov, und des Vorsitzenden des Gebietsexekutivkomitees, Z. Slajkovskij, an das ZK der KPdSU vom 8. April 1960; GAKO, f. 522, op. 1, d. 133, 1. $1 \mathrm{f}$., Brief des Vorsitzenden des Stadtexekutivkomitees, Loškarev, an Gosstroj RSFSR vom 1. Dezember 1964.

${ }^{24}$ Mit statistischen Vergleichen bewegt man sich auf sehr dünnem Eis. Für die Vergleiche Kaliningrads mit anderen sowjetischen Städten wurde im wesentlichen auf die Angaben des statistischen Jahrbuches der RSFSR (Narodnoe Chozajstvo RSFSR v 1956 godu, Moskau 1957, bis Narodnoe Chozajstvo RSFSR v 1970 godu, Moskau 1970) zurückgegriffen, da die Angaben der statistischen Sammelbände, die von den einzelnen Gebietskörperschaften herausgegeben wurden, und die herangezogenen Angaben in Archivquellen zum Teil abweichende Zahlen beinhalten. Die absoluten Werte sind daher mit Vorsicht zu betrachten. Die aus den Statistikwerken gewonnenen Zahlen dienen deshalb nur dem Vergleich von Entwicklungstendenzen.

Die Unsicherheit von Vergleichen zeigt folgende Quelle: Die Versammlung für technische Fragen des Städtebaus beim Stellvertretenden Vorsitzenden des Stadtexekutivkomitees, V. Denisov, prognostizierte am 13. Oktober 1962 für 1965 eine durchschnittliche Wohnraumversorgung in Kaliningrad von 6,5 $\mathrm{m}^{2} /$ Einwohner. (GAKO, f. 522, op. 1, d. 114, 1. 11f.) Laut offizieller Statistik sollte 1960 die Wohnraumversorgung in Kaliningrad schon auf $10 \mathrm{~m}^{2} /$ Einwohner angestiegen sein.

25 Für den Vergleich wurden die durchweg höheren Angaben, die die statistischen Jahrbücher „Narodnoe Chozajstvo RSFSR“ verzeichnen, benutzt, um die Vergleichbarkeit mit den anderen sowjetischen Städten zu ermöglichen, während die im folgenden Abschnitt angeführten Werte, die lediglich einen Vergleich zum Vorkriegszustand herstellen, aus den vorher 
etwa 6 Millionen $\mathrm{m}^{2}$ geschätzt, der Bestand Kaliningrads betrug demgegenüber 1956 lediglich 1,1 Millionen $\mathrm{m}^{2}, 1960$ 1,3 Millionen $\mathrm{m}^{2}$ und 1964 1,6 Millionen $\mathrm{m}^{2}$, von denen zuletzt noch etwa eine halbe Million $\mathrm{m}^{2}$ aus der Vorkriegszeit stammte ${ }^{26}$. Auch die Einwohnerzahlen blieben weit hinter dem Vorkriegsniveau zurück: Erst 1979 erreichte Kaliningrad die Vorkriegsmarke von 380000 Einwohnern ${ }^{27}$. Selbst wenn man annimmt, daß die Kaliningrader Behörden ihre Schätzung des Vorkriegsbestandes übertrieben, um aus Moskau mehr Mittel für den Wiederaufbau der Stadt zu erhalten, so verdeutlicht dieser Vergleich doch den enormen Nachholbedarf Kaliningrads gegenüber Königsberg bis weit über die sechziger Jahre hinaus. Die Statistik zeigt, was die Beschreibungen der Ruinen bereits vermuten lassen, nämlich weshalb Kaliningrad als eine tote Stadt wahrgenommen wurde: Das noch viel kleinere russische Kaliningrad steckte unübersehbar im Ruinenmantel des deutschen Königsberg - es versteckte sich beinahe darin.

\section{Die besetzte Stadt}

\section{In der Fremde}

Das Bewußtsein der Behörden und Parteiorganisationen für die Probleme des Wiederaufbaus war schon sehr viel früher geschärft, als es die zunächst begeisterten Beschreibungen der Ruinen der zu Staub zerfallenen „Zitadelle des preußischen Militarismus" vermuten lassen. Während diese Berichte ebenso wie die Analyse der deutschen Architektur dazu dienten, durch die Stigmatisierung der vorgefundenen Gebäude den sowjetischen Umsiedlern die Aneignung der neuen Umgebung zu erleichtern, stellten die Behörden schon bald fest, daß die Distanzierung von der bestehenden Stadt eine bedenkliche Kehrseite hatte - den Vandalismus.

Weil der dringend benötigte Wohnungsbestand des alten Königsberg auf diese Weise stark dezimiert wurde, befaßte sich der Chef der neugeschaffe-

erwähnten Briefen entnommen wurden. Es bleibt zu überprüfen, ob die unterschiedlichen Angaben im Statistischen Jahrbuch und den Archivquellen auf unterschiedliche Zählweisen zurückzuführen sind: In den Quellen der Kaliningrader Archive sind keine Angaben dazu gemacht, ob Küchen und Bäder zur Wohnfläche hinzugezählt worden sind oder nicht. Üblicherweise werden diese Flächen von der Wohnfläche (poleznaja žilaja ploščad' - Nutzwohnfläche) abgezogen. Die Beobachtung, daß in Kaliningrad Mitte der sechziger Jahre erst ein geringer Teil des Vorkriegsbestandes an Wohnfläche wieder- oder neuaufgebaut worden war, bleibt von diesem Problem allerdings unberührt.

26 So der Kaliningrader Chefarchitekt Vladimir Chodakovskij im Jahr 1963 in: Materialy soveščanija po proektirovanniju centra goroda Kaliningrada, S. 3. 1946 wurden noch $640000 \mathrm{~m}^{2}$ erhaltene und weiterhin nutzbare Wohnfläche in Kaliningrad gemeldet (GARF, f. 374, op. 2, d. 173, 1. 2, zitiert nach: Matthes, Als Russe in Ostpreußen, S. 74).

27 Pravda, 29. April 1989. 
nen städtischen Zivilverwaltung, Vasilij A. Borisov, schon in seinem zweiten Befehl vom Mai 1946 mit diesem Problem. Er stellte fest, „daß Häuser, die noch zum Wiederaufbau taugen, von verschiedenen Organisationen und Personen zerstört werden, indem Dielen, Fenster, Türen und sanitäre Einrichtung herausgerissen werden", und verordnete deshalb den Rayons[Bezirks-]Vorstehern der Zivilverwaltungen, „schnell den Schutz der Häuser $[z u]$ organisieren und deren weitere Zerstörung $[z u]$ stoppen, wofür alle Arbeiter Ihres Rayons zum Kampf gegen die Zerstörung erhaltener Gebäude zu mobilisieren sind. Festgenommene Personen werden als Räuber staatlichen Eigentums vor Gericht gestellt." 28

Der Chefarchitekt der Gebietskommunalverwaltung, Timochin, machte einen Monat später in seinem bereits teilweise zitierten Bericht an Vasilij A. Borisov die "chaotische und ungeplante Besiedlung" des Gebietes und ungeordnete Besetzung von Gebäuden durch die Ankommenden für diese Situation verantwortlich, die zu „einem großen Verlust an Mitteln“ führe ${ }^{29}$. Außerdem, so beschwerte er sich, würden die Armee-Einheiten bei ihrem Abzug die von ihnen verlassenen Gebäude inklusive der Heizungsanlagen ausplündern, „und die Rayon-Vorsteher treten dem nicht entgegen und nehmen die Position unbeteiligter Zuschauer ein oder unterzeichnen formell die Genehmigungen für die Herausgabe“.

Es war zweifelsohne eine psychologisch schwierige Aufgabe für die neuen Einwohner der Stadt, pfleglich mit den von den Feinden übernommenen Bauten umzugehen: Vielen Übersiedlern mag es absurd erschienen sein, eine "deutsche" Stadt wiederaufzubauen, die von der Propaganda als wertlos gebrandmarkt wurde, während andere sowjetische Städte noch in Trümmern lagen ${ }^{30}$. Auch ein Jahr später hatte sich nichts Grundlegendes an dieser mißlichen Lage geändert, als der Parteichef des Kaliningrader Gebietes, Ivanov, im Mai 1947 einen Brief an Stalin schrieb, um ihm die „eigenartige wirtschaftliche und politische Situation“ im Kaliningrader Gebiet zu schildern. Neben der Kritik an der Zivilverwaltung, die sich „nicht um die Produktionsstätten gekümmert“ und es nicht geschafft habe, „revolutionäre Ordnung in das Gebiet zu bringen und wirkungsvoll auf die ökonomische Wiederherstellung des Gebietes Einfluß zu nehmen“, so daß die Industrie nicht einmal den bescheidenen Plan für 1946 erfüllen konnte, fand er harsche Worte für die Moskauer Zentrale: „Die Erfassung und Bewachung der

28 GAKO, f. 237, op. 1, d. 1, 1. 2, Befehl No. 2 des Chefs der städtischen Zivilverwaltung der Stadt Königsberg, Kolov, vom Mai 1946 [ohne Tagesangabe].

29 GAKO, f. 237, op. 1, d. 2, 1. 1, Bericht über die Frage des Wiederaufbaus und der Rekonstruktion der Stadt Königsberg, vom Chefarchitekten der Gebietskommunalwirtschaft, Timochin, für den Chef der Zivilverwaltung des Königsberger Gebietes, Vasilij A. Borisov, vom 26. Juni 1946.

30 Eine ähnliche Beobachtung läßt sich für die Stadt Wroclaw/Breslau machen, aus der in den fünfziger und sechziger Jahren Ziegel für den Wiederaufbau Warschaus abtransportiert wurden. Vgl. Koch, Gestärktes „Breslauertum“. 
Räumlichkeiten und des Beutegutes wurde nicht gebührend organisiert. Sachwerte wurden veruntreut, der Wohnungsbestand und Produktionsflächen zerstört. Vertreter verschiedener Ministerien und Ämter betrachten Ostpreußen als besetztes Gebiet, demontieren die Ausrüstungen, schaffen wertvolle Materialien aus den Betrieben weg, was durch die Regierungsbeschlüsse nicht vorgesehen war. [...] In den drei Monaten seiner Arbeit entstand im Büro des Obkom der VKP die feste Meinung, daß die Ministerien und Behörden die ökonomische und politische Bedeutung des Gebietes unterschätzen, da sie nichts über seine Reichtümer und potentiellen Möglichkeiten wissen und diese auch nicht untersuchen. “ Die Ministerien hätten nur zweitrangige Mitarbeiter „mit begrenztem Horizont“ nach Kaliningrad geschickt, die sich und die Ministerien diskreditierten, indem sie sich an Kaliningrad bereichern wollten.

Ivanov ließ keinen $Z$ weifel daran, daß er in der Bewertung Kaliningrads als besetzte Stadt und nicht als Teil Rußlands eine ernste Bedrohung sah. Die gegenwärtigen Zustände hätten „einerseits bei einem Teil der russischen Bevölkerung Ungewißheiten über ihre Lage auf dem neuem Territorium“ entstehen lassen und „andererseits günstige Bedingungen für die Arbeit der ausländischen Spionagedienste“ geschaffen. Die Bemerkung über die „günstigen Bedingungen" für Spionagedienste war ein deutlicher Hinweis auf die schlechte Stimmung unter den sowjetischen Übersiedlern und eine indirekte Aufforderung an Moskau, dem Gebiet mehr Aufmerksamkeit zu schenken ${ }^{31}$.

Kaliningrad blieb jedoch ein in weiten Teilen unwirtliches Trümmerfeld, und so ist es nicht verwunderlich, daß die Stadt ihren neuen Einwohnern nur eine ungeliebte, zweite Heimat wurde. Viele wären, so wie der im vorigen Kapitel zitierte Übersiedler, am liebsten sofort nach ihrer Ankunft wieder umgekehrt. Selbst die Kader der Kommunistischen Partei scheinen von ihrer Aufgabe nicht immer überzeugt gewesen zu sein: Auf der III. Kaliningrader Parteikonferenz Ende Januar 1950 beschwerte sich der Sekretär des KP-Komitees des Leningrader Rayons, N. Korovkin, über das Verhalten einiger Genossen in den Stadt- und Gebietskomitees. So sei zum Beispiel Genosse P. Ch. Muraško, der Vorsitzende des Stadtexekutivkomitees, nicht zur letzten Sitzung des Stadtsowjet erschienen. Statt dessen sei er in Leningrad gewesen, wo er kürzlich eine Wohnung angemietet habe. „Und noch jetzt", empörte sich Korovkin, „wohnen einige Arbeiter zwar in Kaliningrad, aber im Geiste befinden sie sich in anderen Städten, wo sie rechtmäßig oder unrechtmäßig ihre Wohnungen weiter behalten. Es ist notwendig, entschieden mit diesen ,Kofferlaunen' [čemondannye nastroenija] aufzuräumen, die der Sache Schaden zufügen. Wir sind in Kaliningrad keine Gäste.

31 Alle Zitate aus: CChIDNIKO, f. 1, op. 1, d. 62, 1. 4-9, Brief des Ersten Sekretärs des Gebietskomitees der VKP(b), Jurij P. Ivanov, an Stalin vom 28. Mai 1947. 
Wir sind hierhergekommen, um hier zu arbeiten und zu leben. Kaliningrad ist unsere Heimatstadt.“"32

Die von Korovkin so bezeichneten „Kofferlaunen“ machen einen Verweis zum vorigen Abschnitt notwendig: Die dort zitierten Beschreibungen der Stadt hatten ihren Ausgangspunkt stets am Bahnhof. Dies scheint kein Zufall zu sein, war doch der Blick vom Bahnhof auf die Stadt immer noch der Blick eines Fremden, der gerade in der Stadt angekommen war, nicht aber der Blick eines Einheimischen. Insofern spiegelt sich das Gefühl der Fremdheit in der eigenen Stadt und der mangelnden Verbundenheit der neuen Einwohner mit ihr in diesem Blickwinkel wider. Der Versuch der sowjetischen Geschichtsschreibung, die deutsche Geschichte Ostpreußens als Besatzungszeit slawischer Heimaterde zu werten, schlug fehl, die geistige Identifikation mit dem "rückgewonnenen“ Gebiet mißlang. Der Bahnhof symbolisierte in dieser Lage die Hoffnung auf eine Rückkehr in die alte Heimat.

Eng mit diesem Gefühl der Fremdheit verbunden war die von Ivanov zitierte Unsicherheit eines Teils der russischen Bevölkerung über ihre Lage auf dem neuen Territorium. Durch die faktische Behandlung des ehemaligen Ostpreußen als besetztes Feindesland entstanden unter den sowjetischen Übersiedlern Gerüchte, daß eine Rückgabe der Stadt Kaliningrad an die Deutschen nicht ausgeschlossen se ${ }^{33}$. In gewisser Weise wurde somit das ganze Gebiet als Stalins persönliche Beute angesehen, was nach dem Tod des Generalissimus teilweise zu Panikreaktionen der Umsiedler führte, an die sich Zeitzeugen erinnern: „[...] 1953, da war ein großes Durcheinander. Ja, als Stalin starb, da ging es los. Da hieß es, es gibt Krieg, Krieg, Krieg. Das befürchteten sie damals. Damals sind wir [für fünf Monate] in die Heimat zurückgefahren. "34 Die Heimat - das blieb weiterhin nicht das offensichtlich unsicher erscheinende Kaliningrad, sondern die Region, aus der man gekommen war. Mit einem Besuch am 30. April 1956 versuchte der neue Staats- und Parteichef, Nikita Chruščev, die Bedenken der Kaliningrader zu zerstreuen, ihre Stadt könnte zur Disposition stehen. Welche zentrale Bedeutung diesem in Kaliningrad beigemessen wurde, wird dadurch verdeutlicht, daß nur ein einziger Satz von Chruščevs Rede am Kaliningrader

32 Zitiert aus: III. Kaliningradskaja gorodskaja partijnaja konferencija, in: Kaliningradskaja Pravda, 31. Januar 1950.

33 Siche Teil I dieser Arbeit. Nach dem Ende der Sowjetunion im Jahre 1991 tauchten in regelmäßigen Abständen wieder Gerüchte auf, die Sowjetunion wolle das Kaliningrader Gebiet an Deutschland verkaufen. Vgl. zuletzt: Ihlau, „Bald ist uns Berlin näher“, S. 209. Im Gegensatz zu den Gerüchten, die im Kaliningrad der Nachkriegszeit aufgrund eines Informationsvakuums innerhalb der Bevölkerung entstanden, scheinen die Spekulationen der Nachwendezeit jedoch als Mittel der innenpolitischen Auseinandersetzungen gezielt lanciert worden zu sein.

34 Erinnerung von Aleksandra Ivanovna Mitrofanova, in: Matthes, Als Russe in Ostpreußen, S. 377. 
Flughafen noch fünf Jahre später im neuen Stadtführer zitiert wurde. An die Kaliningrader gewandt, rief er: „Ein Hoch auf die sozialistischen Menschen, die dieses Land erschlossen haben, das unser sowjetischer Boden ist und für ewig bleiben wird!" (Hervorhebung B.H.) Die Zuhörer hatten auf diese aus heutiger Sicht selbstverständlich erscheinende Aussage anscheinend sehnsüchtig gewartet und quittierten Chruščevs Zusicherung mit „stürmischem Applaus"35. Die Dringlichkeit dieses Besuches und vor allem dieses zentralen Satzes der Rede Chruščevs unterstrich im April 1960 der damalige Parteichef des Kaliningrader Gebietes, F. Markov, in einem Brief an das Zentralkomitee: Chruščevs Worte, Kaliningrad werde immer sowjetisch bleiben, hätten „den Kaliningradern eine größere Sicherheit in der Arbeit“ eingeflößt und „bei ihnen eine große politische und schaffende Aktivität“ ausgelöst ${ }^{36}$.

\section{Die Stadt als Steinbruch}

Wie aus dem Brief Ivanovs an Stalin vom Mai 1947 außerdem ersichtlich wird, hatte sich jedoch nicht nur in der einfachen Bevölkerung, sondern auch in der Spitze von Partei und Verwaltung des Kaliningrader Gebietes bald nach dessen Gründung der Eindruck festgesetzt, daß Moskau die Region sich selbst überließ. In seinem Brief an Stalin beschwerte sich Ivanov nicht nur über die Selbstbedienungsmentalität einiger Moskauer Beamter, sondern auch über das Ausbleiben von Investitionen. Da das ganze Stadtzentrum, sein Geschäfts- und Handelsviertel „in Schutt und Asche gefallen“ sei, müsse Kaliningrad „unbedingt in die Gruppe der 15 Städte aufgenommen werden, die durch eine besondere Entscheidung der Regierung zum Wiederaufbau bestimmt worden sind “37. Der Aufbau der Stadt sei bisher jedoch "ohne die ernsthafte Hilfe der Ministerien von Republik und Union" geschehen und nicht in den Nachkriegs-Fünfjahresplan eingegangen: „Wir leben und arbeiten ohne einen einzigen Plan und ohne eine klare Perspektive. Das Kaliningrader Obkom der VKP hat den Ministerien eine ganze Reihe von Fragen über die Ausbeutung von Bernsteinfundstätten, zum

35 Kolganova, Putešesvujte po Kaliningradskoj oblasti, S. 13.

36 CChIDNIKO, f. 1, op. 32, d. 86, 1. 6-8, Brief des Kaliningrader Gebietsparteichefs, F. Markov, an das ZK der KPdSU vom 8. April 1960.1969 durfte der westdeutsche Journalist Dieter Steiner als erster Königsberger Kaliningrad besuchen. Vgl. Steiner, Königsberg ist nicht Kaliningrad, S. 26-36, 138 f. Eine gekürzte Fassung dieser für den Stern geschriebenen Reportage wurde aufgrund Steiners eindeutiger Absage an die Forderung einer Rückgabe der Stadt an die Deutschen in gekürzter Version auch in der Sowjetunion veröffentlicht. Vgl. Steiner, Poezdka v Kaliningrad.

37 Am 1. November 1945 erließ der Rat der Volkskommissare der UdSSR den Erlaß „Über die Maßnahmen für den Wiederaufbau der von den deutschen Besatzern zerstörten Städte der RSFSR: [...]“. Der Rat der Volkskommissare der RSFSR und die nachgeordneten Ministerien wurden darin verpflichtet, in den genannten 15 Städten unter anderem insgesamt $676000 \mathrm{~m}^{2}$ Wohnraum zu errichten. Vgl. Belov, Podnjatye iz ruin, S. $116-118$. 
Schiffsbau, den Wiederaufbau der Stadt usw. gestellt, aber alle diese Fragen werden nur langsam gelöst, ohne den gebührenden Schwung. Statt dessen werden Entscheidungen nur für einzelne Fragen gefällt, die nicht die Probleme im ganzen lösen. "38 Diese Lagebeschreibung läßt vermuten, daß es in Moskau anscheinend keine fundierten Konzeptionen dafür gab, was mit dem neuerworbenen Gebiet in Zukunft anzufangen sei. Zwar wurde vom Ministerrat der RSFSR bereits einen Monat, nachdem Ivanov seinen Brief geschrieben hatte, ein Erlaß „Über die Maßnahmen für den Wiederaufbau der Wirtschaft der Stadt Kaliningrad und des Kaliningrader Gebietes"39 verabschiedet, doch eine Aufnahme Kaliningrads in das 15-Städte-Wiederaufbauprogramm stand in Moskau offenbar nie zur Debatte. Dieses Programm war ausdrücklich für russische Städte bestimmt, die durch die deutschen Besatzer zerstört worden waren. Die Nichtberücksichtigung Kaliningrads zeigt, daß seine Interpretation als eine von deutscher Besatzung befreite Stadt in der Sowjetunion noch nicht besonders tief verinnerlicht worden war. Der Erlaß des Ministerrates der RSFSR von 1947 hatte zudem, ebenso wie ein Folgeerlaß des Ministerrates der UdSSR von 1948 „Über die Hilfsmaßnahmen für den Wohnungsbau und die kommunale Wirtschaft der Städte des Kaliningrader Gebietes" ${ }^{40}$, kaum Auswirkungen auf den Wiederaufbau - und schon 1950 reduzierte die Staatliche Planungskommission (Gosplan) die Hilfsmittel für die Stadt zum Teil um die Hälfte ${ }^{41}$.

Anstatt in Kaliningrad zu investieren, wurde das ehemalige Königsberg als Materialquelle angesehen. So berichtete zum Beispiel ein Leserbriefschreiber der Kaliningradskaja Pravda im Oktober 1952 fassungslos, daß im Moskauer Rayon der Stadt neben Ruinen auch „einige gut erhaltene Häuser abgerissen wurden, um Ziegelsteine zu gewinnen" 42 . Viele dieser so

38 CChIDNIKO, f. 1, op. 1, d. 62, 1. 4-9, Brief des Parteichefs des Kaliningrader Gebietes, Jurij P. Ivanov, an Stalin vom 28. Mai 1947.

39 Erlaß des SM RSFSR vom 27. Juni 1947. Vgl. Butovskaja, Kaliningrad, S. 25.

40 Vgl. CChIDNIKO, f. 1, op. 4, d. 151, 1. 25-32, Bericht des Parteichefs des Kaliningrader Gebietes, Chor'kov, „Über die Erfüllung des Erlasses des Ministerrates der UdSSR ,Über die Hilfsmaßnahmen für den Wohnungsbau [...] der Städte des Kaliningrader Gebietes' vom 11. März 1949".

41 Die Reduzierung um 50 Prozent betraf die Herrichtung von Straßen und Bürgersteigen. Ferner konnten aufgrund der Kürzungen 1951 anstatt geplanter $4000 \mathrm{~m}^{2}$ nur $2400 \mathrm{~m}^{2}$ Wohnraum wiederhergestellt werden. Vgl. CChIDNIKO, f. 1, op. 6, d. 83, 1. 25-27, Brief des Parteichefs des Kaliningrader Gebietes, Vladimir Sčerbakov, und des Vorsitzenden des Gebietsexekutivkomitees, A. Egorov, an den Sekretär des ZK VKP(b) vom 23. November 1950.

Die Reduzierung der Zuweisungen aus Moskau hängt vermutlich auch mit der pauschalen Reduzierung der Mittelzuweisungen im Bausektor um 25 Prozent zusammen, die der Ministerrat am 1. Juli 1950 verordnete, um die Bauorganisationen zum Bau von Typenprojekten zu zwingen. Die Kürzungen für Kaliningrad sind aber trotzdem überdurchschnittlich. Zum Dekret des Ministerrates der UdSSR vgl. Day, Building Socialism, S. $93 \mathrm{f}$.

42 O blagoustrojstve Kaliningrada, in: Kaliningradskaja Pravda, 24. Oktober 1952. Den Abbruch von Häusern, um Ziegelsteine zu erhalten (razborka na kirpič), betrachtete Navalichin hingegen als einzig sinnvollen Umgang mit den zerstörten und beschädigten Häusern des alten Königsberg. In seiner Dissertation dokumentierte er in einer Statistik, wieviel Kubik- 
gewonnenen Ziegelsteine wurden aber nicht für den Wiederaufbau von Kaliningrad, sondern für die Rekonstruktion anderer sowjetischer Städte verwendet. Im September 1954 beklagte sich deshalb der damalige Gebietsparteichef, Vasilij E. Černyšev, beim Ministerrat der UdSSR über einen Mangel an Baumaterialien in Kaliningrad: Vom Moment der Gründung des Kaliningrader Gebietes an sei „ein bedeutender Teil der Ziegel aus dem Abbruch der Gebäude" in Kaliningrad in die angrenzenden Republiken und Gebiete ausgeführt worden, so daß nun, da „die Anzahl der für den Abbruch vorgesehenen Gebäude, bedeutend abgenommen" habe, im laufenden Jahr 1954 „die Bauorganisationen mit Schwierigkeiten bei der Versorgung mit Ziegeln" konfrontiert worden seien. Da die beiden Ziegeleien des Kaliningrader Gebietes ihre gesamte Produktion exportierten, bliebe nunmehr nichts für den Wiederaufbau des Gebietes übrig ${ }^{43}$. Seiner Bitte, mehrere Ziegeleien im Kaliningrader Gebiet wiederaufzubauen bzw. neuzuerrichten, wie dies von einer Spezialistenkommission empfohlen worden sei, wurde jedoch nicht entsprochen. Das Unionsministerium für Baumaterialien stellte in seiner Antwort vom Oktober 1954 lediglich den Bau einer Ziegelei in Aussicht - für mehr sei kein Geld vorhanden ${ }^{44}$. Ein Jahr später schickte das Kaliningrader Gebietsparteikomitee den für Wirtschaftsfragen zuständigen Genossen Puzanov nach Moskau, um bei den Moskauer Ministerien zusätzliche Mittel für den Wiederaufbau Kaliningrads einzufordern. Auch Puzanov hatte keinen durchschlagenden Erfolg: Der Bericht über die Ergebnisse seiner Reise führt nur wenige konkrete Hilfszusagen der Moskauer Behörden auf 45 .

Auch in den sechziger Jahren änderte sich vorerst nichts an der spärlichen Unterstützung für das Kaliningrader Gebiet; 1961 schickte der Ministerrat der RSFSR zwar eine Kommission, die aus Mitgliedern von Gosplan und Gosstroj zusammengesetzt war, nach Kaliningrad, um die von der Gebietsverwaltung erarbeiteten „Maßnahmen zur Beschleunigung des Wiederaufbaus der Stadt Kaliningrad“ zu begutachten, doch trotz der positiven Stellungnahme der Kommission zu diesen Plänen fanden diese Maßnahmen keinen Ausdruck im Staatsplan für das Jahr 1962. Statt dessen, so beschwerte sich der Vorsitzende des Gebietsexekutivkomitees, Ja. Prušinskij, im August 1962 in einem Brief an den Ministerrat der RSFSR, seien die

meter Ziegelsteine aus dem Abbruch der verschiedenen Blöcke der alten Innenstadt gewonnen wurden. Vgl. Navalichin, K voprosu rekonstrukcii centra goroda Kaliningrada, Bd. 1, Anlage 3.

43 CChIDNIKO, f. 1, op. 1, d. 71, 1. 46f., Brief des Kaliningrader Parteichefs, Vasilij E. Černyšev, an den Ministerrat der UdSSR vom 29. September 1954.

44 CChIDNIKO, f. 1, op, 1, d. 71, 1. 48, Brief des Minsteriums für Baumaterialien an das Gebietsparteikomitee VKP(b) vom 18. Oktober 1954.

45 CChIDNIKO, f. 1, op. 18, d. 63, 1. 47-49, Bericht von Puzanov über seine Reise nach Moskau vom 21. November 1955. Als Erfolge konnte er u.a. die zusätzliche Lieferung von 200 Tonnen Zement und $3000 \mathrm{~m}^{2}$ Glas verbuchen. 
Kapitalzuwendungen für die Baubranche des Kaliningrader Gebietes sogar vermindert worden ${ }^{46}$. Aus diesem Grunde sah sich noch 1965 der damalige zweite Sekretär des Parteikomitees des Kaliningrader Gebietes, M. Kudinkin, gezwungen, in Briefen an die Planungsbehörden der benachbarten Sowjetrepubliken um die Zuteilung von jeweils 14 Millionen Ziegelsteinen zu bitten, da aufgrund akuten Baustoffmangels einige Baustellen im Kaliningrader Gebiet bereits eingestellt worden seien ${ }^{47}$. Die Bitten wurden abgelehnt. Fünf Jahre später wiederholte sich dieser Vorgang mit dem gleichen Ergebnis ${ }^{48}$.

Die Einsicht in das langsame Entwicklungstempo der Stadt ließ in den Jahren 1959 bis 1961 sogar die Diskussion um die Lage des Zentrums wieder aufflammen. In offenen Briefen, die die Kaliningradskaja Pravda publizierte, wurde die Meinung vertreten, das vorhandene Zentrum am Platz des Sieges reiche für die Bedürfnisse der Stadt aus - es sei „vollkommen klar“, daß der gesellschaftliche Mittelpunkt Kaliningrads auch weiterhin dort bleiben werde ${ }^{49}$. Einige Kaliningrader konnten der Leere der ehemaligen Altstadt sogar romantische Züge abgewinnen: Wie schön wäre es doch, wenn ein Besucher der Stadt „auf einen freien, völlig unbebauten Platz vor dem Bahnhof gelangt, der in eine schattenspendende Allee entlang der Majakovskaja Straße übergeht", schrieb ein Ingenieur ${ }^{50}$; und ein anderer meinte, die "ungewöhnliche Struktur" der Stadt, in der die Bezirke voneinander „durch schöne Haine getrennt“ seien, müsse „unbedingt erhalten bleiben" 51 .

\section{Wohnungsnot und Planungsprobleme}

\section{„In alten Hütten und Lauben"}

Eine der Folgen der im vorigen Abschnitt beschriebenen Politik war eine große Wohnungsnot in Kaliningrad, die bis in die sechziger Jahre anhielt. Durch den Mangel an Baumaterialien konnten die wenigsten erhaltenen Häuser repariert werden, und viele Ruinen wurden nur notdürftig bewohnbar gemacht. Die Leserbriefspalten der Kaliningradskaja Pravda füllten sich

46 GAKO, f. 297, op. 8, d. 593, 1. 158, Brief des Vorsitzenden des Gebietsexekutivkomitees, Ja. Prušinskij, an den Ministerrat der RSFSR vom 10. August 1962.

47 Vgl. CChIDNIKO, f. 1, op. 43, d. 46, 1. 37, Brief des Sekretärs des Kaliningrader Gebietsparteikomitees, M. Kudinkin, an Gosplan der Litauischen SSR vom 14. Juli 1965. Ebenda, 1. 38, Antwortschreiben von Gosplan mit Negativbescheid.

48 Vgl. CChIDNIKO, f. 1, op. 54, d. 40, 1. 24-28, Briefe des Parteichefs des Kaliningrader Gebietes, Nikolaj Konovalov, an die Parteichefs der baltischen Sowjetrepubliken vom 26. Juni 1970.

49 Gnatenko, Kakim my chotim videt' Kaliningrad, in: Kaliningradskaja Pravda, 5. April 1959.

50 Leserbrief von A. Tjufekčiev, in: Kaliningradskaja Pravda, 8. Mai 1959.

51 G. Krikun, Znakomjaš s planami zodčich, in: Kaliningradskaja Pravda, 4. August 1961. 
mit Beschwerden, wie denen der Bewohner des Hauses der Doktorskaja Straße 31, die sich im August 1950 beklagten, daß ihr Haus „seit einigen Jahren der Zerstörung ausgesetzt ist. Die Dächer sind undicht, Regenwasser rinnt die Wände hinab, die von Schimmel überzogen sind, und die Keller sind mit Müll vollgestopft. "52 Infolge der Wohnungsnot war es in der ersten Hälfte der fünfziger Jahre an der Tagesordnung, daß erst im Rohbau fertiggestellte Häuser bezogen wurden, bevor der Putz getrocknet war, so daß der Innenausbau dieser Häuser kaum vollendet werden konnte ${ }^{53}$.

Im Juni 1955 berichteten Vasilij Černyšev und der Vorsitzende des Kaliningrader Gebietsexekutivkomitees, Z. Slajkovskij, in einem Brief an das ZK der KPdSU und den Ministerrat der UdSSR, das Tempo der Bautätigkeit, des Wiederaufbaus und der Reparatur der Wohnhäuser sei bedeutend niedriger als das Tempo des Wachstums der Bevölkerung der Region, was zu einer „äußerst angespannten Lage bei der Versorgung der Bevölkerung Kaliningrads und anderer Städte mit Wohnraum" geführt habe. In den Städten des Gebietes gebe es eine große Anzahl von Wohnhäusern, die in der unmittelbaren Nachkriegszeit von den Bewohnern selbst provisorisch wohntauglich gemacht worden seien, aber bislang „keine Dächer haben, bei denen einzelne Konstruktionselemente, die Wasserversorgung und die $\mathrm{Ka}$ nalisation zerstört sind. [...] Eine besonders schwierige Lage entstand in der Stadt Kaliningrad, wo ein großer Teil der zerstörten Gebäude, die bewohnt werden, sich in Einsturzgefahr befindet. Zum 1. Mai 1955 gab es in Kaliningrad 111 Havarie-[beschädigte] Häuser, von denen viele nicht einmal für eine Grundinstandsetzung vorgesehen sind. Die übrigen [bewobnten Ruinen] müssen sofort wiederaufgebaut werden, um Unglücksfälle zu vermeiden. In den Havarie-Häusern leben 1330 Familien mit insgesamt 4079 Menschen." 54 Auch in dieser Beziehung brachten die sechziger Jahre keinen Wandel: 1960 lebten nach Angaben des damaligen Parteichefs des Kaliningrader Gebietes, F. Markov, zirka 1500 Familien in Havariehäusern und Ruinen ${ }^{55}$. Etwa 1000 Häuser benötigten in diesem Jahr eine Generalinstandsetzung, für die aber die Mittel bei weitem nicht ausreichten ${ }^{56}$, so daß

52 Podgatovit'každij žiloj dom k zime, in: Kaliningradskaja Pravda, 2. August 1950.

$53 \mathrm{Vgl}$. XIX. Plenum gorodskogo soveta deputatov trudjaščischsja, in: Kaliningradskaja Pravda, 28. Juni 1952.

${ }^{54}$ GAKO, f. 297, op. 8, d. 593, 1. 5 f., Brief des Parteichefs des Kaliningrader Gebietes, Vasilij Černyšev, und des Vorsitzenden des Kaliningrader Gebietsexekutivkomitees, Z. Slajkovskij, an das ZK KPdSU und den Ministerrat der UdSSR vom 30. Juni 1955.

55 Vgl. CChIDNIKO, f. 1, op. 32, d. 86, 1. 6-8, Brief des Parteichefs des Kaliningrader Gebietes, F. Markov, und des Vorsitzenden des Kaliningrader Gebietsexekutivkomitees, Z. Slajkovskij, an das ZK KPdSU vom 8. April 1960.

56 Vgl. CChIDNIKO, f. 1, op. 32, d. 86, 1. 84, Brief des Parteichefs des Kaliningrader Gebietes, F. Markov, an den Leiter Glavsnab RSFSR, S. Kretov, vom 7. Juli 1960. 
noch 1964 ein Architekt feststellte, daß immer noch „eine riesige Menge der Bevölkerung in alten Hütten und Lauben" wohnte"

Die Probleme mit dem Altbaubestand in Kaliningrad sind jedoch nicht nur auf die spezielle Situation im ehemaligen Königsberg - also auf die Ablehnung der deutschen Architektur und die spärlichen Mittelzuweisungen aus Moskau - zurückzuführen, sondern bezeichnen auch einen allgemeinen Systemfehler der sowjetischen Bauwirtschaft. Seit der Gründung des Ministeriums für Städtebau im Jahr 1949 war der quantitative Zuwachs an Wohnraum zu einem zentralen Indikator für den Fortschritt und die Modernisierung der Sowjetunion geworden ${ }^{58}$. Die Qualität der neuerrichteten Wohnungen blieb dabei jedoch oft auf der Strecke. Um die häufig hochgesteckten Planziele zu erreichen ${ }^{59}$, wurden zudem Mittel, die eigentlich für den Erhalt des Wohnungsbestandes vorgesehen waren, für Neubauten zweckentfremdet. Allein zwischen 1959 und 1961 gingen in der gesamten Sowjetunion schätzungsweise 18 Millionen $\mathrm{m}^{2}$ Wohnraum verloren, weil sie nicht rechtzeitig renoviert wurden 60 . Um diesen Zustand zu verschleiern, wurde in vielen sowjetischen Veröffentlichungen zur Statistik nicht der Bestand an Wohnraum, sondern nur dessen Steigerung in Prozent in bezug auf ein Basisjahr der Nachkriegszeit angegeben, in dem der Wohnungsbestand besonders niedrig war, oder es wurde nur der Zuwachs an neu errichtetem Wohnraum verzeichnet, ohne die Abgänge zu erwähnen.

In der Lokalpresse wurde dieser Zusammenhang allerdings offen angesprochen: Neben der Verstärkung des Wohnungsbautempos sei es unumgänglich, so befand 1958 ein Kommentator in der Kaliningradskaja Pravda, „die allerentschiedensten Maßnahmen zu ergreifen, um den bestehenden Wohnungsbestand zu erhalten, ohne den es schwierig sein wird, erfolgreich das Wohnungsproblem zu lösen" 61 . Mangels Mitteln für die Reparatur, aber auch, um die Eigenverantwortung der Bewohner für ihre Häuser zu stär-

57 So der Architekt Gerašmov laut Protokoll der Versammlung der KOSA am 10. Oktober 1964 (GAKO, f. 135, op. 1, d. 62, 1. 14-21).

58 Vgl. Day, Building Socialism, S. 92.

59 Für Kaliningrad vgl. GAKO, f. 520, op. 1, d. 8, 1. 7-12, Expertise von A. N. Kornouchov vom 10. Dezember 1949 zum Schema der vorrangigen Bebauung in der Stadt Kaliningrad und zum Projekt der Bebauung des Stalingrader Prospektes.

Der Experte A. Kornouchov hatte in seinem Bericht den „übertriebenen“ Umfang des geplanten Neubauvolumens kritisiert, der davon ausgehe, daß die Stadt bis 1956 auf 350000 Einwohner (also auf das Vorkriegsniveau) anwachsen würde. Der daraus resultierende Plan, in den nächsten fünf bis sieben Jahren eine Million Quadratmeter Wohnraum zu errichten, sei deshalb unrealistisch. Möglich sei bestenfalls die Errichtung von 220000 Quadratmetern.

60 Vgl. DiMaio Jr., Soviet Urban Housing, S. 21 und $106 \mathrm{f}$., und Ruble, From khrushcheby to korobki, S. 232-270, bes. S. 237 f., der darauf hinweist, daß viele der Ende der 50er Jahre errichteten Häuser aufgrund schlechter Bauausführung und mangelnder Reparaturen bereits zwanzig Jahre später unbewohnbar waren. Nach Kruse, Der sowjetische Wohnungsbau, S. 21, gab es zwischen 1950 und 1960 einen jährlichen Abgang von 17 Prozent der Bruttozugänge an Wohnfläche.

61 Bereč, sochranit' žiloj fond, in: Kaliningradskaja Pravda, 12. Februar 1958. 
ken, wurden in der Kaliningradskaja Pravda außerdem in regelmäßigen Abständen Artikel veröffentlicht, die die Kaliningrader dazu aufriefen, die Reparatur ihrer Häuser selbst in die Hand zu nehmen. Aus Moskau wurde bereits 1950 die Initiative übernommen, den Bewohnern ihre Häuser feierlich in „sozialistische Aufbewahrung“ zu übergeben ${ }^{62}$, ohne daß dies allerdings bemerkenswerte Auswirkungen gezeigt hätte.

\section{Bawarbeiter und Architekten}

Der Neubau von Wohnhäusern stand in Kaliningrad auf ebenso schwachen Füßen wie die Wiederherstellung von beschädigten Gebäuden. Obwohl die Errichtung von Wohnhäusern vom Parteikomitee des Kaliningrader Gebietes als „die wichtigste Voraussetzung für die Stärkung und Herausbildung konstanter Kader für die Industrie Kaliningrads" angesehen wurde ${ }^{63}$, wiederholten sich die Klagen über den schleppenden Fortschritt auf den Baustellen der Stadt ebenso periodisch wie schon die über den nachlässigen Umgang mit den bestehenden Gebäuden. Im Oktober 1949 berichtete der Vorsitzende des Stadtexekutivkomitees, P. Ch. Muraško, in seinem Rechenschaftsbericht auf einer Sitzung des Stadtsowjets, daß die Bautätigkeit in Kaliningrad „immer noch auf dem allerniedrigsten Niveau“ verharre: Der Plan für den Wohnungsbau in Kaliningrad für das laufende Jahr sei erst zu 38 Prozent erfüllt ${ }^{64}$. Ähnlich sah es zwei Jahre später aus: Laut Plan sollten 1951 in Kaliningrad 81 Häuser errichtet bzw. wiederaufgebaut werden, doch war dieser Plan bis Anfang November erst zu 31 Prozent erfüllt ${ }^{65}$. Die Baustelle des Hotels „Moskva“ zum Beispiel wurde 1952 „Dolgostroim“ („Wir bauen lange“) genannt, weil sich die Arbeiten bereits seit Jahren hinzogen ${ }^{66}$. Beinahe monatlich geißelte die Kaliningradskaja Pravda in der Folgezeit die niedrige Planerfüllung67.

62 Žilie doma - na socialističeskuju sochrannost'!, in: Kaliningradskaja Pravda, 7. Dezember 1950.

63 Programma vosstanovlenie i blagoustroistva Kaliningrada, in: Kaliningradskaja Pravda, 24. Februar 1952.

64 XII. Plenum gorodskogo soveta deputatov trudjaščichsja, in: Kaliningradskaja Pravda, 29. Oktober 1949.

65 Vgl. Bystree vvodit' v stroj novye žilie doma, in: Kaliningradskaja Pravda, 12. Dezember 1951. Auch wenn der Plan im Wohnungsbausektor der Sowjetunion noch Ende der 50er Jahre häufig bis zu 50 \% erst im letzten Quartal eines Planjahres erfüllt wurde (wie z. B. in Weißrußland 1958, vgl. dazu: DiMaio, Soviet Urban Housing, S. 21), ist die Planerfüllung in Kaliningrad weit unterdurchschnittlich. Für 1952 sah das Ergebnis in Kaliningrad etwas besser aus: Laut Rechenschaftsbericht des Kaliningrader Gebietsparteikomitees, der am 21. September 1952 veröffentlicht wurde, wurde der Wohnungsbauplan in den ersten sieben Monaten zu 44,2\% erfüllt.

66 Stroiteli i zakazčiki, in: Kaliningradskaja Pravda, 4. Januar 1952. Bis zur Fertigstellung des Hotels im Herbst 1952 veröffentlichte die Kaliningradskaja Pravda noch zwei weitere Artikel über den langsamen Fortschritt bei den Bauarbeiten.

67 So zum Beispiel am 11. und 26. April, 19. Oktober 1954, 14. August 1955. 
Als eine der wesentlichen Ursachen für den langsamen Baufortschritt wurden neben der bereits erwähnten spärlichen Mittelzuweisung aus Moskau gemäß dem Prinzip der Kritik und Selbstkritik in erster Linie die schlechte Organisation auf den Baustellen und die mangelhafte Arbeitskultur der Bauarbeiter genannt ${ }^{68}$. Die auftraggebenden Stellen zeigten kein Interesse daran, ob auf den Baustellen überhaupt etwas geschehe, und es fehlten Absprachen und Verträge mit den ausführenden Baubetrieben, beschwerte sich zudem ein Bauingenieur69. Tatsächlich führten die Zustände auf den Baustellen dazu, daß zuweilen nicht einmal die wenigen für den Wohnungsbau bereitgestellten Mittel komplett aufgebraucht wurden ${ }^{70}$.

Der Vorwurf, zu wenig auf den Baustellen präsent zu sein, traf aber auch die Architekten und Stadtplaner ${ }^{71}$. Das eigentliche Problem der Planung lag hingegen nicht im Verhalten der Architekten, sondern darin, daß es viel zu wenig ausgebildete Architekten gab: „Die Tragödie der Stadt ist das Chaos ihres Wiederaufbaus", hatte ein Architekt bereits 1948 auf der ersten Versammlung der Architekten der Stadt Kaliningrad unter Zustimmung seiner Kollegen festgestellt, und der Chefarchitekt der Gebietskommunalverwaltung, P. V. Timochin, ergänzte, die Ursache für dieses Chaos läge darin, daß in den ersten Jahren seit der Gründung Kaliningrads „die gesamte architektonische Öffentlichkeit im ganzen aus zwei Menschen bestand“72. Die Hoffnung des Leiters der Gebietsabteilung für Architektur, Dimitrij Tjan, der Ende 1947 prophezeit hatte, daß „eine ganze Kohorte von Spezialisten“ das sozialistische Kaliningrad erbauen werde ${ }^{73}$, erfüllte sich jedoch auch nicht, nachdem 1948 mit Dimitrij Navalichin endlich der erste Chefarchitekt für Kaliningrad berufen worden war. Das Gebietsplanungsinstitut (Oblproekt) zeigte sich noch 1953 mit dem vergleichsweise überschaubaren Projekt des Wiederaufbaus und der Umgestaltung des Stalingrader Pro-

68 Vgl. als Beispiel: Programma vosstanovlenija i blagoustrojstva Kaliningrada, in: Kaliningradskaja Pravda, 24. Februar 1952.

69 Stroiteli i zakazčiki, in: Kaliningradskaja Pravda, 4. Januar 1952.

70 Der Kaliningrader Parteichef Vasilij Cernyšev beschwerte sich 1954 in seinem Rechenschaftsbericht für das Jahr 1953, daß von den für den Wohnungsbau im Jahr 1953 freigegebenen Mitteln nur 78\% aufgebraucht worden seien. Siehe: Otčet o rabote Obkoma KPSS, in: Kaliningradskaja Pravda, 13. Februar 1954. Eine ähnliche Beschwerde beinhaltete bereits der am 9. Februar 1952 von der Kaliningradskaja Pravda veröffentlichte Erlaß „O vosstanovlenie i razvitii gorodskogo chozjastva i blagoustroistva goroda Kaliningrada “. Albrecht Martiny beobachtete ähnliche Verhältnisse in der zentralrussischen Stadt Jaroslavl' und führte dies ebenfalls auf die mangelhafte Ausbildung der Bauarbeiter zurück, deren Beruf schlecht angesehen war. Zudem habe es unter der Bauarbeiterschaft durch Saisonkräfte, wie zwangverpflichtete Studenten usw., eine hohe Fluktuation gegeben. Vgl. Martiny, Bauen und Wohnen in der Sowjetunion, S. 66-73.

71 Vgl. III. Plenum Kaliningradskogo Obkoma KPSS, in: Kaliningradskaja Pravda, 1. März 1953.

72 GAKO, f. 522, op. 1, d. 3, Protokoll der ersten Allgemeinen Versammlung der Architekten der Stadt Kaliningrad.

73 Tjan, Sovetskij gorod Kaliningrad, in: Kaliningradskaja Pravda, 7. November 1947. 
spektes überfordert, da nicht genug qualifizierte Kräfte für die Bearbeitung der Bauzeichnungen verfügbar waren ${ }^{74}$. Auch als Vladimir Chodakovskij 1961 sein Amt als neuer Chefarchitekt Kaliningrads antrat, hatte sich die Lage nicht gebessert: Im gesamten Kaliningrader Gebiet zählte er zu diesem Zeitpunkt lediglich zehn Diplomarchitekten. In seinem Bericht über die Lage des Städtebaus im Kaliningrader Gebiet, den er für den Parteichef der Stadt, G. Družinskij, und den Vorsitzenden des Stadtsowjets, N. Korovkin, verfaßt hatte, forderte er deshalb, mehr Architekten in die Stadt zu schicken - Vilnius beispielsweise habe bei gleicher Einwohnerzahl 200 Diplomarchitekten, obwohl dort nicht so viel zu tun sei ${ }^{75}$. Drei Jahre später errang Chodakovskij lediglich einen ziemlich bescheidenen Erfolg, als er in einer Reihe von Briefen die Direktoren der Polytechnischen Institute und Architekturhochschulen bat, Diplomanden nach Kaliningrad zu schicken, um vor Ort Projekte für das hiesige Stadtzentrum ausarbeiten zu lassen, da es in der Stadt selbst zu wenig Architekten gebe, um diese Aufgaben zu bewältigen: Nur zwei Diplomanden aus Litauen erklärten sich bereit, in Kaliningrad zu arbeiten $^{76}$.

Weil es zu wenig Architekten in Kaliningrad gab, wurde ein großer Teil der Planungsarbeit immer wieder an auswärtige Planungsinstitute vergeben, für deren Bezahlung das Gebietsexekutivkomitee Jahr für Jahr Geld beim Staatlichen Komitee für ziviles Bauen und Architektur beantragen mußte ${ }^{77}$. Die Auslagerung der Planungsarbeit war in der Sowjetunion durchaus üblich und vom Ministerium für Städtebau auch erwünscht, da man sich von

74 Vgl. Lapin, Glavnaja Magistral', in: Kaliningradskaja Pravda, 21. April 1953. Bis Chruščev 1957 ein Wohnungsbauprogramm auflegte, um die in der ganzen Sowjetunion verbreitete Wohnungsnot zu beseitigen, besaß der Wohnungsbau allgemein eine niedrige Priorität, und viele sowjetische Städte hatten einen Mangel an Architekten. Großstädte beschäftigten in der Regel 100-200 Architekten in ihrem zentralen Planungsbüro, in Moskau waren es 500. Genauere Vergleichsangaben über die Entwicklung der Beschäftigungszahlen in diesem Bereich gibt es jedoch noch nicht. Vgl. Bater, The Soviet City, S. 36-44.

75 GAKO, f. 522, op. 1, d. 106, 1. 24-26, Brief des Chefarchitekten Kaliningrads, Chodakovskij, an den Parteichef Kaliningrads, G. Družinskij, und den Vorsitzenden des Stadtsowjets, N. Korovkin, vom 13. November 1961. Laut DiMaio war der Mangel an Architekten allerdings ein Problem, mit dem viele sowjetische Städte zu kämpfen hatten. Inwiefern Kaliningrad also tatsächlich im Vergleich zu anderen sowjetischen Städten in dieser Beziehung benachteiligt war, läßt sich noch nicht klären. Vgl. DiMaio, Soviet Urban Housing, S. $16 \mathrm{f}$.

76 Über die Anwerbungsversuche vgl. GAKO, f. 522, op. 1, d. 133, l. 5, Brief des Chefarchitekten Kaliningrads, Vladimir Chodakovskij, an den Rektor des Polytechnischen Institutes von Kaunas vom 29. Mai 1964. Zu den Diplomanden aus Litauen vgl. GAKO, f. 135, op. 1, d. 70, 1. 28, Rechenschaftsbericht der Leitung der Kaliningrader Abteilung der Union der Architekten der Sowjetunion (KOSA) für die Jahre 1964 und 1965 vom 10. Dezember 1965. Darin ist ferner erwähnt, daß die KOSA 1965 immerhin schon 17 Mitglieder hatte, wenngleich dies im Vergleich mit der litauischen Stadt Kaunas, deren Abteilung der SSA 170 Mitglieder zählte, immer noch sehr wenig war.

77 GAKO, f. 297, op. 8, d. 1775, 1. 20, Brief des Stellvertretenden Vorsitzenden des Gebietsexekutivkomitees, G. Chor'kov, an die Staatliche Kommission für ziviles Bauen und Architektur beim Gosstroj SSSR vom 20. August 1965. 
der Zentralisierung eine höhere Effektivität versprach ${ }^{78}$. Nach dem Krieg waren eine ganze Reihe von spezialisierten Planungsinstituten entstanden; von ihnen arbeiteten neben dem bereits erwähnten Giprogor, das den $\mathrm{Ge}-$ neralplan für Kaliningrad entwickelt hatte, unter anderem das "Staatliche Institut für die Planung von Theatern" (Giproteatr), das den Entwurf des Kaliningrader Theaters übernommen hatte, das Leningrader "Zonal-wissenschaftliche Forschungs- und Planungsinstitut" und das "Zentrale wissenschaftliche Forschungsinstitut für Bühnen- und Sportgebäude“ in Kaliningrad. Vor Ort wurde diese Auslagerung der Planung hingegen nicht gern gesehen und führte schon früh zu Unzufriedenheit sowohl unter den Kaliningrader Architekten als auch unter den lokalen Autoritäten. Bereits während der Planung des Neubaus eines Gewerkschaftshauses am zukünftigen Lenin-Prospekt im Sommer 1954 wandte sich Vasilij Černyšev als Parteichef des Kaliningrader Gebietes persönlich an das Präsidium des Gewerkschaftsverbandes (VCSPS) und forderte es auf, den Architekten des gewerkschaftseigenen Planungsinstitutes nach Kaliningrad zu schicken, damit dieser sich das Grundstück, auf dem das Haus entstehen sollte, einmal mit eigenen Augen ansehen könnte ${ }^{79}$. Besonders negativ bewerteten die Kaliningrader Architekten die Arbeit des Moskauer Giprogor: Auf einer Versammlung der KOSA im Dezember 1954 sprach sich der Chefarchitekt von Oblproekt, F. Didenko, dafür aus, „daß die Ausarbeitung der detaillierten Planung der Stadt Kaliningrad vor Ort und von örtlichen Planungsorganisationen durchgeführt werden sollte und nicht durch das Moskauer ,Giprogor ${ }^{\varsigma}$, dem der Auftrag in diesem Jahr übertragen wurde“. Dies würde die Kosten senken und „ohne Streit die Arbeit der Gebietsverwaltung für Architektur bei der Zuteilung von Baugrundstücken erleichtern" 80 . Diese Forderung wurde zu einem Allgemeinplatz unter den Kaliningrader Architekten, die sicher nicht uneigennützig der Überzeugung waren, „ein gutes und richtiges Projekt" für das Stadtzentrum sei nur vor Ort zu planen ${ }^{81}$. Diese breite Ablehnung der Zentralisierung dürfte eine weitere Ursache dafür gewesen sein, daß die Planung von Giprogor für Kaliningrad bis in die sechziger Jahre hinein nicht befolgt wurde. Noch im Jahr 1964, als vom Giprogor eine neue Zentrumsplanung auf den Weg gebracht wurde, sahen die Kaliningrader Architekten in dessen Arbeit im fernen Moskau eine der wesentlichen Ursachen für den schleppenden Fortgang des Wiederaufbaus: „Zu vielen Fehlern [der Stadtplanung] haben die, Giprogor'-Leute beigetra-

$78 \mathrm{Vgl}$. DiMaio, Soviet Urban Housing, S. 72-74.

79 CChIDNIKO, f. 1, op. 1, d. 71, 1. 43, Brief des Parteichefs des Kaliningrader Gebietes, Černyšev, an das Präsidium der VCSPS vom 13. August 1954.

80 GAKO, f. 135, op. 1, d. 19, 1. 6-14, Protokoll No. 2 der Kaliningrader Gebietsversammlung der Architekten vom 25. Mai 1955, hier: 1. 12.

81 GAKO, f. 135, op. 1, d. 19, 1. 52-63, Protokoll der Allgemeinen Versammlung, der KOSA mit Architekten und Ingenieuren aus Kaliningrad vom 30. Juli 1955, hier: 1. 60. 
gen. Die weite Entfernung fördert den engen Kontakt nicht“, wurde auf einer Versammlung der KOSA beklagt ${ }^{82}$. Der damalige Chef der Gebietsabteilung für Architektur, V. Charlamov, stellte deshalb das ganze System der Auftragsvergabe an externe Planungsinstitute in Frage, da auch diese Praxis nicht geholfen habe, genügend Baupläne für Neubauten fertigzustellen. Zudem führe die „Planung der Objekte von außerhalb zu städtebaulichen Fehlern, was die Realisierung der Projekte verzögert". Charlamov plädierte deshalb dafür, das Gebietsplanungsinstitut zu stärken: „Das Institut ist auf der niedrigsten Lohnstufe angesiedelt und hat deshalb keine Möglichkeit, seine Abteilungen mit qualifizierten Kadern zu vervollständigen. Die Staatliche Planungskommission der RSFSR hat dem Institut in den letzten drei Jahren keinen einzigen Architekten oder Ingenieur zugewiesen.“ Um die Planungsarbeit vor Ort zu verbessern, sei es deshalb insbesondere notwendig, daß Gosplan fünf Architekten und acht Ingenieure nach Kaliningrad schicke ${ }^{83}$.

Erschwert wurde die Arbeit der Architekten in Kaliningrad jedoch nicht nur durch die knappe Personaldecke. Auch das Fehlen der Unterlagen der deutschen Stadtplanungsbehörde war ein gravierendes Planungshindernis: Bis in die sechziger Jahre hinein hatten die Architekten in Kaliningrad keinen detaillierten Stadtplan zur Hand. Für die Ausarbeitung einzelner Detailprojekte mußten daher zum Teil gefundene Fragmente deutscher Pläne verwendet werden ${ }^{84}$. Während dieses Hindernis mit der Zeit durch eigene Vermessungsarbeiten behoben werden konnte, blieb eine andere Schwierigkeit bestehen - es gab keine Dokumentation über die unterirdischen Versorgungsleitungen, insbesondere der Kanalisation. Das Kaliningrader Gebietsparteikomitee schickte Mitte der fünfziger Jahre zwei Vertreter nach Berlin, die in den Archiven der DDR jedoch vergeblich nach entsprechenden Unterlagen suchten. Was erst nach 1991 bekannt wurde: Ein großer Teil der benötigten Unterlagen befand sich seit 1945 zusammen mit weiteren Akten, Plänen und Karten der Königsberger Bauverwaltung im Moskauer Sonderarchiv als Geheimsachen unter Verschluß85.

\section{"Die wesentlichen Bauberren der Stadt"}

Eine andere wesentliche Ursache für den langsamen Wiederaufbau Kaliningrads war die Abhängigkeit der Stadt von den Industriebetrieben. Da der kommunale Wohnungsbau wie auch die Konsumgüterindustrie in der So-

82 GAKO, f. 135, op. 1, d. 70, 1. 24 f., Protokoll der Versammlung der KOSA vom 10. Dezember 1965, hier: 1. 25 .

83 GAKO, f. 297, op. 8, d. 2030, 1. 12-14.

$84 \mathrm{Vgl}$. Navalichin, K voprosu rekonstrukcii centra goroda Kaliningrada, Bd. 2, Abb 11,3.

85 Vgl. Ovsjanov, Kenigsberg-Kaliningrad v dokumentach, S. 36. Das Archiv heißt heute „Zentrum für historisch-dokumentarische Sammlungen". 
wjetunion bis in die fünfziger Jahre hinter dem (Wieder-)Aufbau der Schwerindustrie zurückstand, mußten die Betriebe bis 1957 in der Regel selbst für die Unterbringung ihrer Arbeiter sorgen: Das Budget der städtischen Wohnungsverwaltung war, wie in anderen sowjetischen Städten, auch in Kaliningrad für ambitionierte Bauprogramme zu klein, so daß das Wachstum des Wohnungsbestandes, wie der erste Chef der Gebietsverwaltung für Architektur, Dimitrij Tjan, im Sommer 1950 auf einer Sitzung des Stadtsowjets erläuterte, nur von den Industriebetrieben erbracht wurde ${ }^{86}$. $\mathrm{Da}$ nun aber der Wohnungsbau keine originäre Aufgabe der Betriebe war und diese sich vorrangig um den Wiederaufbau der eigenen Produktionsanlagen und die Erfüllung ihres Planes kümmern mußten, betrachteten die Betriebsdirektoren ihn als eine lästige Pflicht. Schon 1949 wurde zudem deutlich, daß ein Teil der Investitionsträger, die eigentlich einen Bauantrag für Wohnhäuser gestellt hatten, gar nicht am Wohnungsbau teilnehmen konnten, weil ihnen die Mittel fehlten ${ }^{87}$. Trotzdem wurden die Betriebe regelmäßig öffentlich dafür kritisiert, daß sie ihrer Aufgabe nicht nachkamen, den eigenen Arbeitern Wohnungen zur Verfügung zu stellen ${ }^{88}$, und es wurde vorgerechnet, mit wieviel Quadratmetern Wohnraum sich ein Werk im Rückstand befand ${ }^{89}$. Selbst die Fischereibetriebe und die drei größten Industriewerke Kaliningrads, bei denen 1955 die meisten Kaliningrader Arbeiter beschäftigt waren, konnten nur einem kleinen Teil ihrer Beschäftigten Wohnungen zuteilen, obwohl sie direkt der Union unterstellt waren und somit besonders gefördert wurden 90 .

Ein weiterer Konflikt zwischen Behörden und Betrieben in Kaliningrad entstand, weil die Betriebe nicht nur zu wenig Wohnungen bauten, sondern zudem die Häuser nicht an den von den Stadtplanern vorgesehenen Stellen, nämlich im Stadtzentrum entlang der Hauptstraßen, errichteten. Das Bauen im Zentrum war vor allem aus ästhetisch-politischen Motiven erwünscht; zur Lösung des Wohnungsproblems trug es hingegen nichts bei oder war dem sogar abträglich. Wie bei der Auseinandersetzung über den Umgang mit der erhaltenen deutschen Bebauung - also dem Streit darum, ob und wie

86 XIX sessija Kaliningradskogo gorodskogo Soveta Deputatov Trudjaščichsja, in: Kaliningradskaja Pravda, 29. Juli 1950.

87 Vgl. GAKO, f. 520, op. 1, d. 8, 1. 7-12, Expertise von A. N. Kornouchov vom 10. Dezember 1949.

Zum Problem der industriellen Bauträger in der Sowjetunion allgemein vgl. DiMaio, Soviet Urban Housing, S. 17f., und über die zentralrussische Stadt Jaroslavl': Martiny, Bauen und Wohnen in der Sowjetunion, S. 62-66.

88 Vgl. Bol’še zaboty o žiliščnom stroitel'stve, in: Kaliningradskaja Pravda, 30. Oktober 1951, über die Kaliningrader Waggonbaufabrik.

89 Vgl. Vyše tempy i kačestvo žiliščnogo stroitel'stva, in: Kaliningradskaja Pravda, 11. April 1954, über das Kaliningrader Zellstoffkombinat.

90 Vgl. GAKO, f. 297, op. 8, d. 593, l. 5 f., Brief des Parteichefs des Kaliningrader Gebietes, Vasilij Černyšev, und des Vorsitzenden des Gebietsexekutivkomitees, Z. Slajkovskij, an das ZK der KPdSU und den Ministerrat der UdSSR vom 30. Juni 1955. 
diese zu erhalten oder umzugestalten sei - handelte es sich bei diesem Streit also vereinfacht ausgedrückt um einen Konflikt zwischen Ideologen und Pragmatikern: Während es den Stadtplanern darauf ankam, zumindest die Hauptstraßen Kaliningrads mit geschlossenen Häuserfronten zu bebauen, um so dem Auftrag der politischen Führung zu entsprechen, ein repräsentatives Stadtzentrum zu schaffen, orientierten sich die Werksleitungen zuvorderst an ihren eigenen Interessen. „Die Industriebetriebe, die die wesentlichen Bauherren der Stadt darstellen", konstatierte daher 1957 der damalige Chefarchitekt Chrustalev, „bemühen sich, die Wohnhäuser in der Nähe der Produktionsstätten zu errichten."91 Vier Jahre später beschwerte sich ein Vertreter des Stadtparteikomitees (Gorkom), daß von den $150000 \mathrm{~m}^{2}$ Wohnraum, die 1959/60 errichtet worden waren, nur $14000 \mathrm{~m}^{2}$ an den Magistralen im Stadtzentrum entstanden seien ${ }^{92}$. Angesichts des vernachlässigbaren Individualverkehrs und der schlechten Verbindungen des öffentlichen Nahverkehrs war dieses Vorgehen verständlich: Der Bau werkseigener Wohnhäuser im Kaliningrader Zentrum, weitab von den Betrieben, hätte den Beschäftigten unnötige Wege durch die Stadt aufgezwungen.

Weil ein freiwilliges Entgegenkommen der Industrie in dieser Frage also nicht zu erwarten war, versuchten die Behörden, die Betriebe zur Errichtung von Wohnhäusern im Zentrum zu verpflichten ${ }^{93}$. Seit 1951 veröffentlichte die Kaliningradskaja Pravda jährlich Erlasse des Gebietsparteikomitees, in denen bis ins Detail festgelegt wurde, welcher Betrieb welches Grundstück an den Hauptstraßen im alten Zentrum zu bebauen hatte ${ }^{94}$. Der bis in die sechziger Jahre hinein nahezu unveränderte Zustand der ehemaligen Innenstadt belegt, wie erfolglos diese Erlasse blieben. Enttäuscht "von der realen Baupraxis in der Stadt", durch die die einzelnen Neubauten „in der Masse der zerstörten Häuser untergehen“, plädierte ein Architekt schon im Jahr 1953 auf einer Versammlung der KOSA deshalb dafür, die „ressortmäßigen Interessen der einzelnen Investitionsträger zu bekämpfen“95. Doch gerade diese „ressortmäßigen Interessen“ schützten viele In-

91 K. Chrustalev, Zastroim central'nye magistrali goroda, in: Kaliningradskaja Pravda, 2. Oktober 1957.

$92 \mathrm{Vgl}$. V. Kirjaev [Stellvertretender Leiter der Abteilung für Industrie und Transport beim Stadtparteikomitee], Lico našego goroda, in: Kaliningradskaja Pravda, 25. Mai 1961.

93 Sie folgten damit der Anweisung, die der Chef der Verwaltung für Architektur beim Ministerrat der RSFSR, Skvvarikov, in einem Befehl vom 14. September 1948 an den damaligen Chefarchitekten von Kaliningrad, Navalichin, erlassen hatte. Vgl. GAKO, f. 520, op. 1, d. 8, 1. $2 \mathrm{f}$.

94 Vgl. zum Beispiel: Programma vosstanovlenija i blagoustrojstva Kaliningrada, in: Kaliningradskaja Pravda, 24. Februar 1952, und O zastrojke i blagoustrojstve central'nich ulic i ploščadej goroda Kaliningrada, in: Kaliningradskaja Pravda, 3. Februar 1954. In der Geschichtsschreibung des Gebietes wurde diesen Erlassen hingegen große Bedeutung und Wirksamkeit eingeräumt. Vgl. Istorija Kaliningradskoj Oblasti. 1951 - 1965, Kaliningrad 1986, S. $41 \mathrm{f}$.

95 GAKO, f. 135, op. 1, d. 11, 1. 4 f., Protokoll der Versammlung der KOSA vom 17. Februar 1953. 
dustriebetriebe vor der Einflußnahme der lokalen Behörden: Die großen Betriebe Kaliningrads wie das Waggonbauwerk, das Zellstoffkombinat und die Werft unterstanden nicht der Gebietsverwaltung. Sie wurden von Ministerien auf Unionsebene verwaltet und waren somit außerhalb des Systems der dualen Subordination unter die regionalen Gremien von Staat und Partei angesiedelt ${ }^{96}$. Über einen großen Teil der Planung von Häusern entschieden deshalb nicht die Verwaltungen oder Parteigremien vor Ort, sondern Beamte in Moskauer Ministerien. Mit diesem Problem hatten alle sowjetischen Städte zu kämpfen; so äußerte sich der Stalingrader Chefarchitekt V. Simbircev 1953 verbittert über den Einfluß der Ministerien auf die Planung: „Dort werden Entwürfe lediglich unter dem Blickwinkel betrachtet, wieviel Flächen sie zur Verfügung stellen und wieviel sie kosten. “97 Mit der Sicherheit, durch die Unterstützung der Industrieministerien am längeren Hebel $\mathrm{zu}$ sitzen, mißachteten die Unions-Unternehmen deshalb regelmäßig die Generalpläne, bauten ihre Gebäude ausschließlich nach den eigenen Bedürfnissen und stellten die Städte damit vor vollendete Tatsachen ${ }^{98}$. Die Erlasse der Partei, in denen den Betrieben vorgeschrieben wurde, wo sie zu bauen hatten, waren daher meist wertlos. Nicht einmal Stalin persönlich schaffte es, die Unternehmen in Moskau zu zwingen, an den Magistralen der sowjetischen Hauptstadt neue Wohnhäuser zu errichten. Trotz eines entsprechenden Befehls von 1949, der im Moskauer Generalplan von 1951 wiederholt wurde, errichteten die Bauträger zwischen 1950 und 1953 nur 22 Prozent der Wohnhäuser an den vom Plan vorgesehen Orten, 64 Prozent wurden dagegen in den Randbezirken errichtet ${ }^{99}$.

Mitte der fünfziger Jahre wurden auf Bestreben Chruščevs Anstrengungen unternommen, diese Situation zu ändern. Seit 1957 waren die Stadtsowjets nominell allein verantwortlich für die Belange des Wohnungsbaus ${ }^{100}$. In Kaliningrad keimte daraufhin die Hoffnung auf, daß nun auch das Zentrum bebaut werden könne, da die Gebietsverwaltung für Architektur nicht mehr "an der Leine von einzelnen Wirtschaftsorganisationen"101 liefe und somit der Primat der Politik über die Wirtschaft wiederhergestellt schien. An dem Grundproblem änderte sich jedoch bis in die sechziger Jahre hinein nichts ${ }^{102}$. Von den $380000 \mathrm{~m}^{2}$ Wohnraum, die $1961-1966$ im Zentrum von Kaliningrad gebaut werden sollten ${ }^{103}$, wurde nur ein kleiner Teil realisiert.

96 Vgl. Bater, The Soviet City, S. 42.

97 V. Simbircev, Ob odnom nerazrešennom voprose, in: Architektura SSSR 8 (1953), S. 31, zitiert nach: Day, Building Socialism, S. 100. Zu diesem Problem siehe auch: Zéle, Programs and problems of city planning, S. 19-59.

98 Vgl. DiMaio, Soviet Urban Housing, S. 66-68.

99 Vgl. Day, Building Socialism, S. 98.

100 Vgl. DiMaio, Soviet Urban Housing, S. 46.

101 Šarin, Čtoby gorod byl krasivyj, in: Kaliningradskaja Pravda, 25. Februar 1960.

102 Noch auf dem XXIII. Parteitag der KPdSU forderte der damalige Vorsitzende des Moskauer Stadtexekutivkomitees, V. Promyslov, die Rechte der lokalen Sowjets endlich wirk- 
Diese Entwicklung wurde von den Behörden durch ihr widersprüchliches Verhalten begünstigt: $\mathrm{Da}$ weder die Stadt noch die Industrie in der Lage waren, die Bevölkerung mit Wohnraum zu versorgen, wurden die Kaliningrader auch in diesem Fall - wie schon bei der Frage der Reparatur von Häusern - dazu aufgerufen, die Sache in die eigenen Hände zu nehmen: So veröffentlichte die Kaliningradskaja Pravda am 2. Februar 1957 unter der Überschrift „Was diejenigen wissen müssen, die ihr Haus selber bauen“ einen Artikel mit Musterplänen für kleine Einfamilienhäuser. Schon wenige Wochen später, am 15. März, mahnte dagegen Navalichin am gleichen Ort unter der Überschrift „Brennende Fragen des Wiederaufbaus“, keine niedrigen Holzhäuser in der Stadt zu bauen, um die Bebauung der Magistralen nicht zu gefährden.

\section{Typenbauweise}

Die Bebauung gerade des Kaliningrader Stadtzentrums scheiterte hingegen nicht nur an dem eben beschriebenen faktischen Primat der Wirtschaft über die Politik. Ein weiterer Hemmschuh war der Vorrang der Menge des errichteten Wohnraums vor der symbolisch-politischen Aussage der Stadtlandschaft. Bei der Frage, an welcher Stelle Wohnhäuser errichtet werden sollten, zeichnete sich insofern innerbalb von Architektur und Städtebau ein Übergewicht des wirtschaftlichen über den politischen Aspekt ab.

Für die Bebauung des Stadtzentrums bedeutete die Priorität der Quantität im Wohnungsbau aus zwei Gründen einen weiteren Stillstand: Zum einen wurden Ende der fünfziger Jahre und in der ersten Hälfte der sechziger Jahre keine öffentlichen Gebäude errichtet ${ }^{104}$ und die ehrgeizigen Pläne für einen gesellschaftlichen Mittelpunkt der Stadt im Bereich der Schloßruine deshalb vorerst auf Eis gelegt. Folgenschwerer war aber, daß in der Sowjetunion in dem Bestreben, möglichst viel Wohnraum $\mathrm{zu}$ errichten, schon in der Spätphase der Stalin-Ära gefordert wurde, zur Bebauung mit typisierten Gebäuden überzugehen ${ }^{105}$. Nach Stalins Tod im März 1953

sam zu stärken, vgl. Pravda, 8. April 1966, zitiert nach: DiMaio, Soviet Urban Housing, S. 66. Über den immer noch starken Einfluß der Betriebe auf die Stadtplanung in den sechziger Jahren vgl. Reiner, Planning and Decision-Making in the Soviet City, S. 49-71, bes. S. $59 \mathrm{f}$.

103 V. Mateev, Zavtra našego goroda, in: Kaliningradskaja Pravda, 20. April 1961.

104 Vgl. GAKO, f. 522, op. 1, d. 106, 1. 24-26, Bericht von Chefarchitekt Chodakovskij für den Parteichef Kaliningrads, G. Družinskij, vom 13. November 1961 über die Lage des Städtebaus im Kaliningrader Gebiet; und: GAKO, f. 297, op. 8, d. 1775, 1. 9, Brief des Vorsitzenden des Stadtexekutivkomitees, Ja. Prušinskij, an das Kulturministerium der RSFSR vom 27. April 1965.

105 Nach Meinung von Day, Building Socialism, S. 90-94, äußerte sich in dem Bemühen des Regimes, die Versorgung der Bevölkerung mit Wohnraum zu verbessern, der Versuch, mit den Menschen einen „Big Deal“ abzuschließen. Er bezieht sich hierbei auf Vera Dunham, In Stalin's time: Middle-class values in Soviet fiction, Cambrigde 1976, die den Versuch der 
machte sich sein Nachfolger Nikita Chruščev daran, diese Richtung energischer weiterzuverfolgen. Auf dem Allunions-Baukongreß vom Dezember 1954 läutete er eine entschiedene Wende ein, die zu einer Industrialisierung des ganzen Wohnungsbaus führen sollte. Nach seinen Angaben arbeiteten im Jahr 1954 von den etwa 1100 sowjetischen Planungsbüros nur 152 mit typisierten Bauelementen ${ }^{106}$. Bereits im August desselben Jahres hatte er deshalb den Bau von 602 neuen Fabrikationsstätten für die Herstellung von Stahlbetonfertigteilen dekretiert ${ }^{107}$. Es dauerte einige Jahre, bis sich die Industrialisierung und Typisierung durchsetzte, da viele Bauarbeiter mit der neuen Technik nicht vertraut waren ${ }^{108}$, doch nachdem der Übergang Anfang der sechziger Jahre endgültig vollzogen war, ergab sich ein neues Problem für die Stadtplaner: Die Typenhäuser waren zu unflexibel, um sie in den Stadtzentren zu verwenden - sie wurden meist in den Vororten aufgebaut, wo sie nebeneinander auf ein freies Feld gesetzt werden konnten, ohne daß auf bestehende Strukturen zu achten war ${ }^{109}$.

In Kaliningrad kam verschärfend hinzu, daß dort Anfang der sechziger Jahre nur zwei Typen von Wohnhäusern zur Anwendung kamen ${ }^{110}$. Gestaltungsmöglichkeiten für Architekten waren somit kaum vorhanden. Um einen völligen Stillstand bei der Bebauung der Innenstadt zu vermeiden, deren politisch-symbolische Bedeutung weiterhin unbestritten blieb, gab es nur zwei Auswege: entweder die weitestgehende Abräumung der alten Bebauung im Zentrum, um sie tauglich für den Bau von Typenprojekten zu machen, oder die Rekonstruktion wiederaufbaufähiger Gebäude. Navalichin hatte sich in seiner Zeit als Chefarchitekt und danach als Chef der Gebietsverwaltung für Architektur bekanntlich für eine konsequente Abwendung von der deutschen Architektur ausgesprochen. Die teilweise Realisierung seiner Pläne für einen Umbau des Zentrums in der zweiten Hälfte der fünfziger Jahre verdankt sich deshalb wahrscheinlich gerade der Tatsache, daß sein radikaler Umgang mit der vorgefundenen Umgebung den

politischen Führung der Sowjetunion beschreibt, Ende der vierziger Jahre die eigene Legitimation zu erweitern, indem sie der Bevölkerung ein Recht auf Konsumgüter und Privatleben zugestand.

106 Chruščevs Rede vom 7. Dezember 1954 ist in gekürzter Fassung von der Stroitel'naja gazeta am 29. Dezember 1954 veröffentlicht worden. Eine Übersetzung findet sich unter anderem in: Martiny, Bauen und Wohnen in der Sowjetunion, S. 167-182.

107 Vgl. Martiny, Bauen und Wohnen in der Sowjetunion, S. 96.

108 Vgl. Martiny, Bauen und Wohnen in der Sowjetunion, S. 41-48. In Navalichins Dissertation findet sich ein Foto, wie 1957 die Betongroßblöcke für die ersten Typenhäuser in Kaliningrad von Hand in Holzformen hergestellt werden.

109 Bereits Anfang 1950 beschwerten sich Experten des Ministeriums für Städtebau, daß in Stalingrad trotz des großen Umfanges der Bautätigkeit der städtebauliche Erfolg sehr unbefriedigend sei, da keine Hauptstraße im Zentrum der Stadt vollständig bebaut sei. Vgl. Day, Building Socialism, S. 96.

110 Vgl. GAKO, f. 522, op. 1, d. 106, 1. 24-26, Bericht des Chefarchitekten Chodakovskij an den Parteichef der Stadt Kaliningrad, G. Družinskij, über die Lage des Städtebaus im Kaliningrader Gebiet. 
Einsatz von Typenprojekten ermöglichte. Die Pläne von Giprogor nahmen sich daneben antiquiert aus, da sie im wesentlichen dem alten Straßenmuster folgten und deshalb individuelle Entwürfe für die Gebäude voraussetzten. Navalichin betonte 1958, im Planungsschema von Giprogor sei nicht beachtet worden, „daß die neue Bebauung der Blöcke, die im wesentlichen mit modernen Typenprojekten realisiert wird, sich faktisch nicht an dem früher bestehenden Netz von Straßen und unterirdischen Versorgungsleitungen orientieren kann". Die neue Bebauung erfordere hingegen einen ganz neuen Maßstab ${ }^{111}$. Der großflächige Abriß der Ruinen in der nördlichen Innenstadt zwischen Schloßruine und ehemaliger Ostmesse seit Ende der fünfziger Jahre entsprach somit nicht nur der von Navalichin geforderten $\mathrm{Ab}$ kehr von der deutschen Stadt, sondern war auch Vorbedingung für die Neubebauung mit Typenprojekten. Insofern griffen in Navalichins Projekt in einer paradoxen Weise modernisierende und konservative Bestrebungen ineinander, die bis in die sechziger Jahre hinein die Ablehnung der Vorkriegsarchitektur zementierten.

Das Scheitern des Neuaufbaus, ob mit oder ohne Typenprojekten, setzte aber seit der zweiten Hälfte der fünfziger Jahre den bereits erwähnten Umwertungsprozeß in Gang, in dessen Verlauf versucht wurde, die "Gehäuse“ (korobki) der zerstörten Häuser verstärkt in den Aufbau miteinzubeziehen. Schon 1960 hatte der damalige Kaliningrader Chefarchitekt L. Iljuchin in der Kaliningradskaja Pravda die Meinung vertreten, manche Ruinen könne man „im ursprünglichen Zustand wiederaufbauen, rekonstruieren oder ihre Fundamente benutzen", um so Geld und Baumaterial zu sparen"112. Vier Jahre später hatte sich auch der Vorsitzende des Stadtexekutivkomitees, N. Loškarev, dieser Meinung angeschlossen und schrieb einen Brief an Gosstroj RSFSR mit der Bitte, in der Stadt 15 Prozent nichttypisierte Wohnhäuser errichten zu dürfen, um die Ruinen im Stadtzentrum, „die einen großen Wert darstellen“, wiederaufbauen zu können ${ }^{113}$. Auch beim Wiederaufbau von Ruinen tauchte allerdings das Problem der Industrialisierung des Bausektors auf, das ihn nach Ansicht von Iljuchins Nachfolger Chodakovskij entscheidend erschwerte: „Im Zusammenhang mit dem gegenwärtigen Übergang zu industriellen Baumethoden, bei denen vorgefertigte Elemente benutzt werden, ist beim Wiederaufbau von Ruinen mit nichttypisierten Abmessungen eine Anwendung der vorhandenen typisierten Elemente praktisch unmöglich. Beim Wiederaufbau dieser Ruinen wird im wesentlichen nichtmechanisierte Handarbeit angewendet." Aus diesem Grunde nahmen die Baubetriebe den Wiederaufbau von Ruinen nur ungern in An-

111 Navalichin, K voprosu rekonstrukcii centra goroda Kaliningrada, S. 103.

112 L. Iljuchin, Protiv besplanovosti v zastrojke Kaliningrada, in: Kaliningradsjaka Pravda, 2. Februar 1960.

113 GAKO, f. 522, op. 1, d. 133, 1. 1 f., Brief des Vorsitzenden des Stadtexekutivkomitees, Loškarev, an Gosstroj RSFSR vom 1. Februar 1962. 
griff, und selbst die Rekonstruktion von Gebäuden, für die es schon Pläne gab, verzögerte sich ${ }^{114}$. Hemmender als der Unwille lokaler Baubetriebe wirkte sich aber auch in diesem Fall der zentralisierte Entscheidungsprozeß auf den Wiederaufbau aus: Die Moskauer Behörde Gosstroj behielt sich vor, über den Wiederaufbau jeder Ruine einzeln zu entscheiden. Bevor in den sechziger Jahren ein zerstörtes Haus in Kaliningrad wiederhergerichtet werden konnte, mußte die Stadtverwaltung daher erst eine detaillierte Dokumentation des Projektes mit Grund- und Aufrissen, einem Gutachten über die vorhandene Bausubstanz, Fotos der Ruine und Unterlagen über die für den Wiederaufbau veranschlagten Mittel nach Moskau zur Prüfung schicken $^{115}$.

\section{Zukunftssehnsucht}

Auch wenn der Erwartungshorizont der sowjetischen Neusiedler an die neue Heimat schon bei ihrer Ankunft beträchtlich gesenkt wurde, so nahm doch die Entwicklung der Stadt in den folgenden Jahrzehnten einen unerwartet unerfreulichen Verlauf. Hatte die Kaliningradskaja Pravda noch 1948 siegesbewußt verkündet, daß die „junge sowjetische Stadt Kaliningrad“ in einem solchen Tempo wiederaufgebaut werde, „wie es die Städte in den kapitalistischen Ländern nicht kennen" ${ }^{116}$, so häuften sich spätestens seit Mitte der fünfziger Jahre die oben beschriebenen kritischen Stellungnahmen über den nur mühsam fortschreitenden Wiederaufbau. Sorgfältig wurde bei dieser Kritik jedoch darauf geachtet, den Vergleich Kaliningrads mit Königsberg aus der öffentlichen Diskussion herauszuhalten - Überlegungen von Architekten und Parteigenossen in diese Richtung wurden deshalb vorwiegend intern angestellt und finden sich dementsprechend auch fast nur in Schriftstücken, die nicht zur Veröffentlichung bestimmt waren ${ }^{117}$.

Um so aufmerksamer wurden von der Partei hingegen die Publikationen der Vertriebenenpresse über Kaliningrad studiert, die einen Vergleich des Vorkriegszustandes Königsbergs mit der aktuellen Situation der Stadt an-

114 GAKO, f. 297, op. 8, d. 593, 1. 125, Antwort vom 17. Juli 1962 des Chefarchitekten Chodakovskij auf einen Leserbrief in der Kaliningradskaja Pravda vom 15. Juli 1962.

115 GAKO, f. 522, op. 1, d. 133, l. 2f., Brief von Gosstroj an das Stadtexekutivkomitee vom 14. Februar 1964 (Antwort auf dessen Schreiben vom 1. Februar 1964).

116 Kaliningradskaja Pravda, 7. April 1948, zitiert nach Matthes, Als Russe in Ostpreußen, S. 176.

117 Eine der wenigen Ausnahmen stellt die Bemerkung des damaligen Chefarchitekten K. Chrustalev in dem Artikel "Zastroim central'nye magistrali goroda" dar, den die Kaliningradskaja Pravda am 2. Oktober 1957 publizierte. Darin schrieb Chrustalev, daß alle Städte ein historisch gewachsenes Zentrum mit hohen, schönen Häusern besäßen, von dem aus alle Teile der übrigen Stadt gut erreichbar seien. Königsberg habe „alle diese Merkmale“ gehabt, Kaliningrad aber besitze gegenwärtig überhaupt kein Zentrum. 
stellten. Im ehemaligen Gebiets-Parteiarchiv der KPdSU haben sich einige russische Übersetzungen solcher Artikel erhalten, bei denen die roten Unterstreichungen zeigen, welche Aussagen die Leser im Kaliningrader Gebietsparteikomitee besonders auffielen. So hatte das Ostpreußenblatt unter der Überschrift „Heute im nördlichen Teil Ostpreußens“ im März 1963 unter Bezug auf eine sowjetische Veröffentlichung über Kaliningrad unter anderem geschrieben: „Aber wenn heute Königsberg von etwa 200000 Menschen bewohnt wird, dann heißt das bei den russischen Wohnverhältnissen, daß noch die Hälfte der Stadt in Trümmern liegt.“ Einen Absatz weiter wurde die Bemerkung unterstrichen: „... von einer Universität wird nichts gesagt." 118 Ohne die Stadt mit eigenen Augen gesehen zu haben, hatten die Autoren mit diesem Artikel eine empfindliche Stelle des Selbstbewußtseins der Kaliningrader berührt. Wie sehr diese Berichte die Parteispitze treffen mußten, wird schon allein aus der Tatsache ersichtlich, daß das Kaliningrader Gebietsparteikomitee bereits während der Vorbereitung zur Feier des zehnjährigen Bestehens des Kaliningrader Gebietes das ZK der KPdSU gebeten hatte, das Kaliningrader Pädagogische Institut anläßlich dieses Jahrestages in eine Universität umzuwandeln - weil Königsberg eine Universitätsstadt gewesen war ${ }^{119}$.

Der Deputierte des Kaliningrader Gebietes im Obersten Sowjet und Gebietsparteichef, Nikolaj Konovalov, zeigte sich von solchen Artikeln derart empört, daß er sich zu einer Art Vorwärtsverteidigung entschloß. In einem Kommentar für die Literaturnaja Gazeta, der später von der Kaliningradskaja Pravda übernommen wurde, schrieb er 1967: „Die Herren aus Westdeutschland wollen sich nicht darin schicken, daß auf der Erde des ehemaligen Ostpreußen ein neues sowjetisches Gebiet geschaffen wurde, sich entwickelt und festigt - ein Vorposten des Friedens im Westen unserer Heimat." Die Produktion der Kaliningrader Industrie sei mittlerweile sechsmal höher als vor dem Krieg, und die Kaliningrader Fischer fingen mehr Fische als alle Fischer Westdeutschlands zusammen. Die Autoren des Ostpreußenblattes hätten nicht bemerkt, daß anstelle der von ihnen beschriebenen Ruinen in Wahrheit Neubauten stünden 120 .

118 CChIDNIKO, f. 3928, op. 9, d. 2, Übersetzung des Artikels „Heute im nördlichen Ostpreußen. I. Teil. Königsberg", in: Das Ostpreußenblatt No. 10, 9. März 1963. In der Akte befinden sich noch weitere Übersetzungen, unter anderem von Artikeln aus der Heimatbrücke. Sämtliche Artikel erschienen in den sechziger Jahren.

119 CChIDNIKO, f. 1, op. 18, d. 55, 1. 59, Brief des Kaliningrader Parteichefs, Vasilij Černyšev, an das ZK der KPdSU vom 28. Dezember 1955 mit Vorschlägen im Zusammenhang des zehnjährigen Bestehens des Kaliningrader Gebietes.

120 Konovalov, Molodoj kraj sovetskoj Rossii, in: Kaliningradskaja Pravda, 11. Mai 1967 (zuerst abgedruckt in: Literaturnaja Gazeta, 9. Mai 1967). Die durch den schlechten Zustand Kaliningrads entstandene Angst vor einer Blamage könnte jedoch einer der Gründe gewesen sein, weshalb Kaliningrad so lange eine geschlossene Stadt war. Noch 1987 soll der damalige außenpolitische Berater Gorbačevs, Georgi Arbatov, gesagt haben, daß Kaliningrad „einfach noch nicht vorzeigbar sei“. Vgl. Ihlau, Einmal Kaliningrad bitte! 
Konovalovs Kommentar ist wahrscheinlich in erster Linie für das Ausland konzipiert gewesen, um auf die schon erwähnte „Aufmerksamkeit westlicher Führer" für die Lage im ehemaligen Königsberg zu reagieren. Sehr viel beunruhigender als die Meinung von Vertriebenen waren für die örtlichen Parteivertreter allerdings die negativen Auswirkungen des Zustandes Kaliningrads auf die Stimmung in der Stadt. Diesen Auswirkungen versuchte man entgegenzuwirken, indem zum Beispiel die Kaliningradskaja Pravda schon frühzeitig demonstrativ die Erfolge des Wiederaufbaus feierte. So verkündete Navalichin 1950, zwei Jahre nachdem er sein Amt als Kaliningrader Chefarchitekt angetreten hatte: „In der ganzen Stadt gibt es keine Ecke, an der nicht gebaut wird. Vor kurzen wurden von den Wohnhäusern in der Pugačev-, Engels-, Offizierskaja und Kommunalnaja Straße die Gerüste abgenommen. Bald werden die Arbeiter von Kaliningradvodstroj die Montage des Daches des Wohnhauses am Stalingrader Prospekt vollendet haben. [...] Aber all das ist nur der Anfang des grandiosen Aufbaus des zukünftigen Kaliningrad. In den kommenden zwei Jahren wird das Bautempo erhöht." 121 Im ersten Nachkriegsjahrzehnt wurde beinahe jedes fertiggestellte Wohnhaus abgelichtet und mit Bildunterschriften wie „Der Morgen Kaliningrads“ oder „Kaliningrad baut auf und wächst“ der Leserschaft präsentiert ${ }^{122}$. Sofern es kein Gebäude gab, dessen Fertigstellung zu feiern war, wurde in den fünfziger Jahren ersatzweise über die sogenannten „subbotniky“ oder „voskreseniky“ berichtet: mehr oder weniger freiwillige Arbeitseinsätze von angeblich bis zu 35000 Kaliningradern an Wochenenden, bei denen in der Regel Aufräum- oder Gartenarbeiten durchgeführt wurden. Wenn schon keine Ruinen wiederaufgebaut werden konnten, so sollten doch wenigstens schöne Blumenrabatten das Auge erfreuen ${ }^{123}$. Auch kleine Erfolge wurden als große Errungenschaft gepriesen, so zum Beispiel die Aufstellung der neuen Straßenlaternen am Stalingrader Prospekt anläßlich des zehnten Jahrestages der Erstürmung Königsbergs - der ersten StraBenbeleuchtung in der Stadt seit Kriegsende ${ }^{124}$.

In diesen Zusammenhang gehören auch die zahlreichen Veröffentlichungen in der lokalen Presse über einzelne Bauprojekte und die grandiosen Umgestaltungsvorhaben, die noch gar nicht in Angriff genommen worden waren. Ihre Präsentation täuschte eine Dynamik der Stadtentwicklung vor, die sich angesichts der Gigantomanie der Pläne Navalichins nie einlösen ließ. Kaliningrad befand sich dabei in der gleichen Lage wie viele andere kriegzerstörte Städte, für die nach 1945 neue Generalpläne geschaffen wurden: „Mit diesen Projekten“, so der Historiker Andrej Ikonnikov, „sollten

121 Navalichin, Naš gorod zavtra, in: Kaliningradskaja Pravda, 7. April 1950.

122 So zum Beispiel am 1. Oktober 1950 und am 31. Oktober 1951.

123 Entsprechende Berichte zum Teil mit Fotos wurden unter anderem am 22. April, am 10. Juli 1951 und am 15. Februar 1952 in der Kaliningradskaja Pravda veröffentlicht.

124 Maljonikov, Kaliningrad segodnja, in: Kaliningradskaja Pravda, 9. April 1955. 
ausgedehnte zusammenhängende Systeme aus öffentlichen Ensembles geschaffen und entwickelt werden, hinter denen keine realen Investitionsquellen standen und für die es keine Funktionsprogramme gab [...] Die Utopie artete zur Phantasie aus, die ihren Wert in sich selbst hatte und von den realen Lebensbedingungen unabhängig war." 125 Die Planung für die großen Ensembles hatte somit vor allem eine Aufgabe - mächtige Ideen sollten die Macht des Staates und der Partei verdeutlichen ${ }^{126}$.

Auch nach dem Ende der Stalin-Ära änderte sich nichts an der Tendenz, Potemkinsche Städte zu errichten: Noch Mitte der sechziger Jahre meinte der Vorsitzende der KOSA, Eremeev, man müsse gegenüber der Kaliningradskaja Pravda in Zukunft besser klarstellen, welche Projekte sich noch in der Planungsphase befänden und welche tatsächlich zur Realisierung anstünden ${ }^{127}$. Die virtuelle Rundfahrt durch die Stadt der Zukunft, bei der die Pläne so dargestellt werden konnten, als seien sie bereits realisiert, blieb aber ein beliebtes Stilmittel der lokalen Presse ${ }^{128}$. Diese Ausflüge spiegelten jedoch nicht nur das stete Bemühen der Behörden wider, den Einwohnern der Stadt das sichere Nahen besserer Zeiten zu verkünden - sie entsprachen auch der Zukunftssehnsucht der Kaliningrader, die mit der Gegenwart unzufrieden waren, eine Zukunftssehnsucht, die der Architekt S. Grin'kov in seinem bereits zitierten Stoßseufzer offen ansprach, als er schrieb: „Wie sehr wünschen wir Kaliningrader uns, daß [...] die Ruinen und Brachflächen vollständig verschwinden! Wir versuchen nicht selten in die Zukunft zu blicken, uns vorzustellen, was hier gebaut wird und wie dann die Stadt aussehen wird." 129

Gegen den für Kaliningrad unvorteilhaften Vergleich mit dem Königsberg der Vorkriegszeit setzte die Partei die Betonung der Kriegszerstörungen und der seitdem geleisteten Aufbauerfolge. So wird im ehemaligen Kaliningrader Gebietsparteiarchiv ein Foliant aufbewahrt, der etwa 1958 entstand. Der Foliant ist in zwei Teile gegliedert; der erste Abschnitt ist mit „Die Folgen des Krieges“ überschrieben und zeigt das zerstörte Königs-

125 Ikonnikov, Architektur und Utopie, hier: S. 35.

126 Allerdings ist zu bemerken, daß zwar, von Stalingrad und Novgorod abgesehen, kaum ein sowjetisches Stadtzentrum nach den Plänen der vierziger und fünfziger Jahre vollendet wurde, viele Innenstädte jedoch trotzdem von den stalinistischen Bauten dieser Zeit beherrscht werden, wie zum Beispiel Moskau (Hochhäuser), Voronesh, Kiev, Sevastopol, Charkov u.a.

127 GAKO, f. 135, op. 1, d. 70, 1. 27-31, Rechenschaftsbericht des Vorsitzenden der KOSA, Eremeev, vom 10. Dezember 1965.

128 Als Beispiel kann der Artikel von V. Kormil'cev, Ėto budet zavtra, in: Kaliningradskaja Pravda, 1. Januar 1969, dienen, in dem sich der Autor gedanklich ins Jahr 1975 versetzt, mit dem Taxi durch die Innenstadt fährt und sich die neuen Gebäude ansieht. Die gleiche Vorgehensweise läßt sich in sowjetischen Städten schon seit Mitte der dreißiger Jahre beobachten, so zum Beispiel in Moskau, bevor der Generalplan von 1935 überhaupt offiziell verabschiedet war. Vgl. Intourist, Moscow. Past, present, future, Moskau 1934, S. 137-149.

129 Grin'kov, Glazami zodčich, in: Kaliningradskaja Pravda, 21. September 1965. 
berg, der zweite Abschnitt trägt den Titel „Kaliningrad heute“ und enthält eine Reihe von Fotos von Neubauten und Denkmälern. Dieses Album entstand drei Jahre nachdem der westdeutsche Rautenberg-Verlag anläßlich des 700-jährigen Stadtjubiläums der Stadt Königsberg im Jahr 1955 den Bildband „Königsberg in 144 Bildern“ herausgegeben hatte, ein Buch mit alten Fotografien der Stadt vor ihrer Zerstörung ${ }^{130}$. Der prächtig ausgestattete und handgefertigte Kaliningrader Foliant war offensichtlich als Reaktion auf den westdeutschen Bildband gedacht: Er trägt auf dem aufwendig aquarellierten Deckblatt den Titel „700 Jahre Gebiets-, Industrie- und Kulturzentrum, bedeutender Hafen an der Ostsee, Stadt Kaliningrad. 144 Fotografien"131. Diese sonderbare Mischung von wahrscheinlich ironisch gemeinter Adaption der Stadtgeschichte und dem Verweis auf den sozialistischen Wiederaufbau sollte demonstrieren, wie wenig von der alten Stadt geblieben war und wie hoch folglich die Leistungen nach $1945 \mathrm{zu}$ bewerten waren. Beim Betrachter stellt sich angesichts einiger Fotos des Wiederaufbaus allerdings ein gegenteiliger Eindruck ein: Es fällt auf, wie isoliert viele Neubauten inmitten der Trümmerwüste waren.

Anfang der sechziger Jahre wurde der Versuch unternommen, die Aufbauerfolge in ein besseres Licht zu rücken, indem der Eindruck, die Stadtentwicklung mache keine Fortschritte, zu einem Wahrnehmungsproblem erklärt wurde. Im Winter 1960 und Frühjahr des folgenden Jahres erschien in der Kaliningradskaja Pravda eine Artikelserie mit dem etwas trotzigen Titel „Das haben wir selbst gemacht“. Auch hier wurde ausführlich die Ausgangslage in der kriegzerstörten Stadt erörtert, und Einwohner Kaliningrads berichteten, was sie zum Wiederaufbau beigetragen hatten. Das Ziel dieser Artikel war es, die Leserschaft zu überzeugen, daß der Anschein des Stillstandes beim Wiederaufbau im wesentlichen durch den zu nahen Blickwinkel der Kaliningrader Bevölkerung erzeugt werde. Sie mußte deshalb an die Hand genommen und durch die Stadt geführt werden, um ihr die Augen $z u$ öffnen für Dinge, die sie selbst nicht wahrnahm. Ein bemerkenswertes Beispiel für diese Argumentation ist ein Artikel, in dem die Autorin beschreibt, wie sie mit einer Bekannten, die schon seit einigen Jahren nicht mehr in Kaliningrad gewesen sei, durch die Straßen der Stadt spazierte. Verwundert registrierte sie die Begeisterung ihrer Bekannten über Kaliningrad.

„ Ja, das ist ja eine andere Stadt, eine völlig neue Stadt', wiederholte sie jede Minute. Ich verstand anfangs diesen verzückten Zustand irgendwie nicht, doch dann versuchte ich, mir unsere Stadt so vorzustellen, wie sie früher war. Und dann verstand ich meine Bekannte. Uns Kaliningradern fällt es schwerer, den krassen Wandel im Anblick unserer Stadt zu bemerken, wir haben uns hier eingelebt, wir gehen jeden Tag durch ihre Straßen, und so wie die Mutter nicht das Größerwerden ihres Kindes bemerkt, so bemerken auch 
wir mitunter nicht, wie hier und dort schöne und helle Häuser emporwachsen, wie ein dünnes Zweiglein, das liebevoll neben einen Weg gesetzt wurde, sich in einen fülligen, grünen Baum verwandelt, wie an der Stelle von Ruinen Parks und Grünanlagen erblühen."

Das abschließende Eingeständnis der Autorin, daß „zu der Zeit, zu der sich andere Städte schon an ein friedliches Leben gewöhnten", sich in Kaliningrad tatsächlich „noch bei jedem Schritt der durchstandene Krieg fühlbar" machte, nahm die negative Wahrnehmung der zerstörten Stadt durch die Kaliningrader auf, um sie sogleich umzuwerten, indem diese Zeit als abgeschlossene Vergangenheit erschien, die nun von einer erfolgreicheren Gegenwart abgelöst wurde ${ }^{132}$.

Um die Entwicklung Kaliningrads seit seiner Annexion durch die Sowjetunion zu beschreiben, benutzte auch der Architekt S. Grin'kov einige Jahre später, in einem Artikel vom April 1964, eine Wachstumsmetapher, indem er die neunzehn Jahre der sowjetischen Geschichte der Stadt mit den Lebensphasen eines Menschen verglich. Die von den Kaliningradern beklagte und von Grin'kov eingestandene Verzögerung im Aufbau der Stadt erklärte er somit zu einer natürlichen Entwicklungsstufe: Neunzehn Jahre im Leben eines Menschen - das sei „die Zeit der Jugend und des Erwachsenwerdens. Eben diese Zeit durchlebt nun unsere Heimatstadt Kaliningrad. Sie erhob sich aus dem Staub, gewann an Stärke, streckte die Schultern und schreitet sicheren Schrittes in die Zukunft."133 Diese Deutung weitergedacht, erscheint es ganz selbstverständlich, daß Kaliningrad bisher aufgrund seiner „Kindheit" und „Jugend" noch keine vollwertige Stadt war, nicht auf eigenen Füßen stehen konnte, sondern noch der fremden Hilfe bedurfte. Gleichzeitig wird auch hier wieder die nun endlich erfolgte Wende zum Besseren beschworen, visualisiert durch das Bild des "sicheren Schrittes“, mit dem die nun erwachsene Stadt in die Zukunft schreite.

Bildhafte Interpretationen der Stadtentwicklung blieben auch in den folgenden Jahren fester Bestandteil der Lokalberichterstattung über den Aufbau Kaliningrads. Besondere Begeisterung löste der Bau des „Mikrorayons No. 1“ aus, dessen Bau 1965 begonnen wurde. Dieses erste flächendeckende Neubaugebiet in Kaliningrad seit 1945 entstand im nördlichen Teil des alten Stadtzentrums zwischen Schloßruine, Lenin-Prospekt, Unterteich und ehemaliger Ostmesse. Unter der Überschrift „Veränderungen“ beschrieb ein Autor die Arbeiten im Sommer 1966 als einen „Angriff“, der dort von Bauunternehmen auf „breiter Front“ durchgeführt werde, und fuhr fort: „Ich habe mich nicht versprochen und übertreibe auch nicht, wenn ich die Be-

132 Odna iz mnogich - ulica Narvskaja, in: Kaliningradskaja Pravda, 3. Dezember 1960. Die weiteren Artikel der Serie erschienen am 1., 11. und 18. Dezember 1961, am 16. und 28. Februar und am 9. und 30. März 1962.

133 Grin'kov, Molodet' rodnomu gorodu!, in: Kaliningradskaja Pravda, 4. April 1964. 
griffe ,Front' und ,Angriff‘ benutze. Betrachten Sie das Gelände zwischen den Straßen Astronomičeskaja und Sergeeva, und Ihrem Blick eröffnet sich das Panorama eines Sturmangriffes. Auf die Brachfläche brechen Wohnhäuser ein. Die einen sind schon bis zum Dach fertig, bei anderen werden die Mauern errichtet und dritte sind schon bezugsfertig. [...] Reihenweise fahren Lastwagen Betonblöcke und Platten heran. Das Gekrache der Dieselramme und menschliche Stimmen, das Knirschen von Bulldozern, die Trümmer beiseite schieben, alles verschmilzt zu einer einzigen Bausymphonie." 134 Zwanzig Jahre nach Kriegsende war in Kaliningrad die Nachkriegszeit zu Ende. 